\title{
Alcayota Gum Films: Experimental Reviews
}

\author{
Marisa Zanon, Martin Masuelli* \\ Laboratorio de Investigación y Servicios de Química Física (LISeQF-UNSL), Instituto de Física Aplicada-CONICET y \\ AQF-DQ-FQByF-Universidad Nacional de San Luis, San Luis, Argentina \\ Email: *masuelli@unsl.edu.ar
}

How to cite this paper: Zanon, $M$. and Masuelli, M. (2018) Alcayota Gum Films: Experimental Reviews. Journal of Materials Science and Chemical Engineering, 6, 11-58. https://doi.org/10.4236/msce.2018.65002

Received: April 13, 2018

Accepted: May 25, 2018

Published: May 28, 2018

Copyright (C) 2018 by authors and Scientific Research Publishing Inc. This work is licensed under the Creative Commons Attribution International License (CC BY 4.0).

http://creativecommons.org/licenses/by/4.0/

(c) (i) Open Access

\begin{abstract}
Polysaccharides obtained from plant have been investigated for the development of edible/biodegradable non petrochemical-based packaging materials. Alcayota (Curcubita ficifolia) is the fruit of a creeping plant such as watermelon and melon. It is the fruit of a creeping plant such as watermelon and melon. After separating the pulp from the husk and seeds it is dried and ground to obtain a flour. Different alcayota flour is made to hydrolyze then. Alkaline hydrolysis is released to extraction of alcayota gum and is purified by hydroalcoholic solutions. The films were prepared from water solution of hydrolyzed alcayota gum ( $\mathrm{AlcOH})$. AlcOH film present properties are mainly due to the strong hydrophilicity. In order to improve water resistance, the films were modified using glutaraldehyde (Glu), in order to make the water insoluble film. The crosslinked films providing a low water vapor permeability (WVP) and high mechanical properties expressed in elastic modulus. The $\mathrm{X}$-ray diffraction showed amorphous and shift to lower $\mathrm{d}_{\text {spacing, }}$ i.e. at lower distances between the polysaccharide chains. These crosslinked membranes exhibit excellent water resistance, low $\mathrm{O}_{2}$ permeation, which make them very useful in selecting biodegradable polymer and films.
\end{abstract}

\section{Keywords}

Cucurbita Ficifolia, Alcayota Gum, Biopolymer, Films, Crosslinking

\section{Introduction}

Synthetic plastics, due to their accumulation and their long decomposition time, generate a great environmental problem. Research efforts for the development of film and coatings from biorenobable material are carried out, where the raw material to prepare biodegradable film is renewable biopolymer, which are very abundant in nature and inexpensive. These materials can be obtained from urban waste, of biological origin, and agroindustrial. The raw material to produce 
films and biodegradable coatings are polysaccharides such as cellulose, the most abundant, starch as the most developed and widespread culture, alginate the most abundant in oceans, pectin, as a waste in several citrus crops, etc., and chitosan, the most versatile and of many applications. The vast majority of polysaccharides can form films and coatings with good barrier properties against the gas transport such as oxygen and carbon dioxide. The excellent mechanical properties of the tensile strength and the percentage of elongation are very important when designing a biopackaging. The objective of these biopackages is to maintain the integrity of the food. The tensile strength values shown by the films based on polysaccharides vary from one another, but some of them exhibit values similar to those observed in the values of synthetic polymers [1].

An edible coating is a thin layer of edible material on the surface of the food product, while an edible film is a preformed and independent thin layer of edible material, which once formed can be placed on or between the food components. The purpose of edible films and coatings is to protect and preserve the food from biodegrading agents for a certain time [2]. There is also the non-edible film, which may or may not be in contact with the food and whose purpose is to protect from external agents and preserve the food. One of the main characteristics of this type of films is that it is water insoluble and allows the partial passage of gases. The disadvantage is the possibility of the migration of undesirable substances to the food, for this reason it requires very exhaustive studies to certify the biopackaging [3].

The development of edible films, coatings and non-edible films is an environmentally friendly technology that would permit a reduction in the impact and disposal costs associated with synthetic polymer films. Edible films, coatings and non-edible films can be used as active packaging, extending the shelf life in a wide variety of food applications by preventing dehydration, microbial growth, oxidative rancidity, surface browning, and oil diffusion [4].

Oxygen is one of the main problems in food preservation, since it has a harmful effect on the quality of it. Edible films, coatings and non-edible films can include antioxidant agents in their formulation and at the same time, they represent a barrier to oxygen, which results in a better preservation of quality [5]. The water activity of the product, as well as the ambient relative humidity, determines the antioxidant effect of edible films, coatings and non-edible films [6]. Different polysaccharides have the potential to be used as film formers, a review of different works in this regard can be consulted according to the following reference [7].

\subsection{Classic Film Forming Polysaccharides}

Methyl cellulose (MC) membranes were prepared and were crosslinked with glutaraldehyde (GA) at different concentrations. The results showed that the addition of GA decreased water solubility, swelling, water vapor permeability of MC films, and the release of antioxidant substances from the active materials in- 
creased with the concentration of GA [8].

Starting $\beta$-glucan and protein polymers from barley to prepare biodegradable film. These films have high stiffness, high thermal stability, decreased water solubility, and reduced water vapour permeability. These results show a strong structural network established through physical and chemical interactions between the protein and $\beta$-glucan polymer chains [9].

A study of biodegradable and edible cassava starch-glycerol based films with different concentrations of yerba mate extract was prepared by casting. The presence of yerba mate extract led to a decrease in the degradation time of the films in soil ensuring their complete biodegradability before two weeks and to films stability in acidic and alkaline media [10].

Films made from triticale flour activated with natamycin for cheese packaging. The addition of natamycin reduced solubility values and water permeability, and antifungal activity inhibit deterioration [11].

Films of trimethylammonium-2-hydroxypropyl (TMAHP) spacer and heparin (H) TMAHP $+\mathrm{H}$ were quaternized. The film mechanical properties were better on $\mathrm{H}$ with elastic modulus, $\mathrm{E}=4030 \mathrm{MPa}$, and then on quaternized specimens, $\mathrm{E}=2500-3340 \mathrm{MPa}[12]$.

Composite films of low methoxyl pectin (LMP) with addition of carrot fiber (CF) of different particle size were crosslinked with $\mathrm{Ca}^{2+}$. The films showed the lowest hydration capability and produced the least elastic and antioxidant activity associated to the loaded CF [13].

A film-forming material was gum ghatti (GG) with addition of plasticizer as sorbitol and glycerol. Sorbitol-GG films had lower moisture content, water contact angle, water vapor permeability and oxygen permeability but higher water solubility than glycerol-GG ones. Tensile strength and elastic modulus of films decreased with plasticizer concentration; X-ray diffraction showed an amorphous-crystalline structure of films and crystallinity index decreased with increasing plasticizer concentration [14].

Biocomposite films were processed by extrusion and compression molding starting of Agar/soy protein, obtaining transparent and homogeneous films. The biocomposite films showed with differential scanning calorimetry (DSC) and specific mechanical energy (SME) values, and during the extrusion process protein denatured and unfolded protein chains could interact with agar, and these interactions were supported by the decrease of film solubility [15].

Kappa-carrageenan (SRC) based edible films plasticized with glycerol or sorbitol. These films containing plasticizers had higher tensile strength and elongation at break than the control (unplasticized) SRC film. SRC films plasticized with sorbitol were more effective oxygen barriers [16].

Chitosan films with ciprofloxacin hydrochloride, CFX, were produced with the aim to achieve a topic controlled drug delivery system for ciprofloxacin hydrochloride. The release was easily controlled by the degree of crosslinking with tripolyphosphate and addition of AgNPs. The purpose of this work is to evaluate 
the antimicrobial effect of CFX and AgNPs-CFX loaded chitosan films against Pseudomonas aeruginosa presenting a similar inhibition zone than the CFX controls and higher than the chitosan films [17].

Red rice flour (RRF) and red rice starch (RRS) were used for prepared biodegradable films with glycerol as plasticizer rate. Among the films studied, RRF-RRS (9:1) film showed improved mechanical properties and lower cost compared with rice starch-based film and exhibited great activity in scavenging the DPPH radical (>90\%) [18].

Sodium alginate (SA) composite films what has three types of nanofillers: graphene oxide (GO), ammonia functionalized graphene oxide (AGO), and triethoxylpropylaminosilane functionalized silica. Where interaction between AGO and SA increase in stability and mechanical strength of composite films. The tensile strength and elongation at break of AGO/SA composite film at $3 \mathrm{wt} \%$ AGO loading were increased in contrast to pure SA film [19].

Paper cups were achieved by physically blending sodium alginate (SA) and gellan gum with crosslinking treatment $\left(\mathrm{Ca}^{2+}\right)$. Results demonstrated excellent compatibility between the two polysaccharides. The blended films showed the synergistic effect between SA and gellan gum, which can be used for water-resistant film coating on paper cups for hot drinks [20].

Pectin is a polysaccharide with characteristic of biodegradability, biocompatibility, edibility, and versatile chemical and physical properties, such as gelation, selective gas permeability, etc. Pectin is a suitable biopolymeric matrix for the elaboration of edible films intended as active food packaging for prevents the microbial growth by extending the lag period and reducing the growth rate of microorganisms [21].

The blend film made from binary solutions of gum tragacanth (GT) and locust bean gum (LBG) at different mixing ratios, present homogenous and smooth surface morphology and their transparency, water vapour barrier and mechanical properties were improved by incorporating LBG in blend [22].

Biodegradable xanthan $(\mathrm{X})$ and glycerol $(\mathrm{G})$ films were prepared at a molar ratio $[\mathrm{G}] /[\mathrm{X}]<3.0$, for maximize crosslinking were used mono-glycerol instead by poly-glycerol in order to improve its properties [23].

Casting method were using for prepare tara gum (TG)/polyvinyl alcohol (PVA) blend films. These films presented a tensile strength increased from 20.71 $\mathrm{MPa}$ to $44.74 \mathrm{MPa}$ and that the contact angle increased from 55.95 to 90.0 with increasing ratio of TG/PVA from 90/10 to 70/30. The barrier properties, oxygen and water vapor permeability, and UV barrier ability were also enhanced with the addition of PVA [24].

Agar films were preparing from native agar (NA) and alkali-modified agar (AA) and mixed with locust bean gum (LBG). Agar films present mechanical properties and water resistance were optimal for films with 50 and/or 75\% LBG contents and best in the case of NA (cheaper to extract) [25].

Hyaluronan of molecular weight of $500 \mathrm{kDa}$ was modified with 
$\mathrm{N}$-(3-dimethylaminopropyl-N-ethylcarbodiimide hydrochloride (EDC) and $\mathrm{N}$-hydroxysuccinimide (NHS). The modified hyaluronan this film is made materials water insoluble with mechanical and viscoelastic properties of revealed the high dependency of elasticity changes depending on the gel processing method [26].

Water insoluble films based on palmitoyl esters of hyaluronan were prepared with properties in accordance with the polymer degree substitution and molecular weight and being non-cytotoxic [27].

\subsection{New Film Forming Polysaccharides}

The Alyssum homolocarpum seeds gum film (AHSG) present the followship characteristics: moisture of $23.13 \%$, solubility of $13 \%$, contact angle of $74.60^{\circ}$, oxygen permeability of $45.9 \mathrm{~cm}^{3} \mathrm{~m} / \mathrm{m}^{2} \mathrm{~d} \mathrm{kPa}$, WVP of $44.09 \mathrm{~g} \mathrm{~mm} \mathrm{m-2} \mathrm{d-1}$ $\mathrm{kPa}^{-1}, \mathrm{Tg}$ of $63.86^{\circ} \mathrm{C}$ and $\mathrm{Tm}$ of $100.92^{\circ} \mathrm{C}$ [28].

Flammulina velutipes gum, FVG, was prepared as edible films. FVG film had the optimal mechanical property and good barrier property to water (37.92 \pm $2.00 \mathrm{~g} \mathrm{~mm} / \mathrm{m} 2 \mathrm{~h} \mathrm{kPa})$ and oxygen $(37.92 \pm 2.01 \mathrm{meq} / \mathrm{kg})[29]$.

Novel edible film based on chia mucilage with addition of glycerol. When glycerol concentration increased, water vapor permeability (WVP), elongation at break (EB), and water solubility of Chia mucilage films increased while their tensile strength (TS), and Young's modulus decreased significantly, exhibited excellent absorption of ultraviolet light, and good thermal stability [30].

Camelina gum (CG) film were evaluated, with $4 \%$ nanoclay, tensile strength of film increased from 43.2 MPa to 54.6 MPa without change elongation property, obstruct the diffusion of water, thereby decreasing the water vapor permeability, and ultraviolet light transmittance decreased by $40 \%$ with $10 \%$ nanoclay [31].

Hsian-tsao gum (HG) and casein (CAS) films were prepared, and the results showed that the addition of HG gave the CAS film better mechanical properties and moisture resistance, with stronger barrier properties against light and higher antioxidant activities that pure CAS film [32].

Dracocephalum moldavica seed mucilage (DMSM) as a novel film-forming material with addition of glycerol $(10 \%-40 \%, w / w)$, presenting to measure that concentration increased, the films' water vapour permeability, elongation at break (\%EB), water solubility, and moisture content significantly increased and on the contrary tensile strength, surface hydrophobicity, melting point, and glass transition point $\left(\mathrm{T}_{\mathrm{g}}\right)$ decreased significantly [33].

Basil seed gum (BSG) as a new film-forming material under the influence of addition of glycerol (GLY) as plasticizer. Edible films based on BSG and three different concentrations of GLY (25\%, 35\%, and 50\% w/w BSG) were developed. The addition of glycerol increased water vapor permeability and solubility of the film, with increased the extensibility, but decreased tensile strength. The BSG had a good potential to be used in producing edible films for various food applications [34]. 
Soluble soybean polysaccharide (SSPS) nanocomposite incorporating $\mathrm{ZnO}$ nanoparticles. The nanocomposites were presented the antibacterial and anti-mold activities, indicated that incorporating of nanoparticles affect the tensile strength and elongation at break significantly [35].

Mucilage extracted from Opuntia ficus-indica cladodes (Cactaceae) was used for prepared films with different plasticizers as glycerol, sorbitol, PEG 200 and PEG 400. The significant effect of polyol type plasticizers on the different properties of mucilage edible films was related to their structural features that promote different interactions with mucilage polysaccharides [36].

Branched dextrans with high molar masses and controlled architecture were synthesized using a dextransucrase and branching sucrases, present glass transition between $40.5^{\circ} \mathrm{C}$ and $63.2^{\circ} \mathrm{C}$ for water content varying from $12.2 \%$ to $14.1 \%$, with a storage modulus which varies from 2 to $4 \mathrm{GPa}$ [37].

Edible film from Balangu seed mucilage (BSM) and glycerol has superior mechanical and barrier characteristics with a potential candidate for packaging that aim at an extended shelf-life [38].

Fenugreek seed gum (FSG)/clay nanocomposite films were prepared with nanoclays at different amounts by solution casting method. FSG based nanocomposite films exhibited strong antimicrobial properties, where mechanical properties of nanoclay incorporation up to $5 \%$ provided higher tensile strength and elongation at break values significantly decrease [39].

Films from xylan-based hemicelluloses (XGP), were made from beech wood xylan (WPG) was firstly modified with p-dioxanone through ring-opening graft polymerization and then reinforced by poly(vinyl alcohol) (PVA) to get xylan-graft-poly(p-dioxanone)/PVA (XGP/PVA) ternary composite films. From differential scanning calorimetry (DSC) data, the miscibility between XGP and PVA led to increase in the glass transition temperature ( $\mathrm{Tg}$ ) and the crystallinity, with thermogravimetric analysis (TGA) curves indicated that the addition of PVA improved the thermal stability of XGP, tensile testing showed a dramatic increase in the elongation at break of films with the development of weight percent gain (WPG) of XGP [40].

The synthesis of citric acid crosslinked carboxymethyl tamarind gum (CMTG) hydrogels films were conducted, this has a swelling decreased with increase in curing temperature and time, with non-Fickian release mechanism suggesting controlled release of drug [41].

Cashew gum (CG), an exudate polysaccharide from Anacardium occidentale trees, was carboxymethylated (CGCm) and oxydized (CGO) and films were produced through layer-by-layer (LbL) assembly with chitosan via electrostatic interactions or Schiff bases covalent bonds [42].

Arabinoxylans (AX) from wheat bran in order to further investigate the impact of their composition and structure on several physic-chemical properties used for food packaging films. When arabinose content decreased, the films were more crystalline and the beta transitions decreased as well as the water uptake at 
high relative humidity [43].

Beech wood xylan (BX) was carboxymethylated (CMX) and hydroxypropylated (HPX) with addition of glycerol were achieved aimed to produce bio-based films. These membranes have tensile strength, Young's modulus and water vapour permeability high and the elongation at break lower than those of the corresponding HPX films; with oxygen barrier property was exceptionably good for a CMX film plasticized with $25 \%$ of glycerol and high oxygen permeability values were obtained for HPX films [44].

FucoPol membranes were prepared by incorporation of a $\mathrm{SiO}_{2}$ network homogeneously dispersed by using a sol-gel method with GPTMS as a crosslinker silica precursor and crosslinked with $\mathrm{CaCl}_{2}$ for reinforcement of mechanical properties and improvement of their permeation performance. They membranes presented a dense and homogeneous structure, resistant to deformation, with a $\mathrm{T}_{\mathrm{g}}$ of $43^{\circ} \mathrm{C}$ and a thermal decomposition between $240^{\circ} \mathrm{C}-251^{\circ} \mathrm{C}$ [45].

\subsection{Pumpkins and Similar Polysaccharides Film Forming}

Pectin from melon [46], watermelon [47] [48] [49] possessing great capacity to form gels and emulsions, therefore, can also form films for food and pharmaceutical applications.

It should be noted that both polysaccharides extracted from melon and watermelon, although they are similar to the Cucurbit family, but they present particular characteristics. Below we will describe works of the Cucurbit family, regarding studies in the production of films for different applications.

Although there are many works on polysaccharides obtained from pumpkins (cucurbit genus) [50] [51]. These polysaccharides are obtained by different extraction techniques, hydrolysis, etc. [52] [53] [54] [55]. They also have potential film formers and with excellent properties for various applications, as hypoglycemic [56], antioxidant, etc. [57] [58] [59] [60].

The polysaccharides from pumpkin (Cucurbita moschata Duch.) peels, presented a range of molecular weight $13-205 \mathrm{kDa}$ [61], $21.1 \mathrm{kDa}$ [62], very encouraging data as additives or film formers.

The polysaccharides from Cucurbita maxima Duch. from cell walls were affected syntheses of some galactosidic polysaccharides in pectin, hemicellulose [63] and xyloglucans [64] [65].

Pectic polysaccharides from oil pumpkin (Cucurbita pepo L. var. Styriaca) by a different extraction procedure at various reaction conditions. They founded the first four fractions comprised partially methyl-esterified and acetylated pectins with varying proportions of rhamnogalacturonan regions ramified with galactose- and arabinose-containing side chains and showed considerable polymolecularity; contained lower amounts of pectins with homogalacturonan and arabinose-rich rhamnogalacturonan regions next to hemicelluloses prevailing in the last polysaccharide [66]-[71].

Extractions performed to Cucurbita pepo [72] [73] by different separative 
techniques showed that the polysaccharide obtained is rich in galactose with hypoglycemic and hypolipidemic effects might be beneficial in diabetic patients.

The water-soluble heteropolysaccharide from pumpkin, Cucurbita pepo Lady Godiva, comprised L-fucose, D-galactose, D-glucose, and D-mannose, the glycosidic linkages consisted of 1,2,6- and 1,6-substitued-galactopyranosyl, 1,4,6- and 1,3substitued-glucopyranosyl, terminal-glucopyranosyl, and terminal-fucopyranosyl, with a molecular weight of $10.1 \mathrm{kDa}$ and it can be an additive to form blend films with other types of macromolecules such as proteins or other polysaccharides [74] [75] [76].

Studies carried out on polysaccharides obtained from Cucurbita ficifolia account for the many pharmaceutical applications that this gum possesses, as anti-diabetic drugs [77] [78] [79] [80].

Pumpkin oil cake (PuOC) addition to gelatin in attempt to form biodegradable composite films, achieving properties like tensile strength (TS) had the film made of gelatin/PuOC $60 / 40 \%$, with glycerol, compared to pure gelatin film. Elongation to break (EB) increased with increase of PuOC \% in films, and when

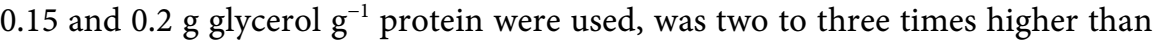
EB of $100 \%$ gelatin film. Swelling properties, as well as solubility, color and antioxidant activity showed that film, with similar or improved properties could be produced, when PuOC was added to gelatin [81].

Pumpkin oil cake $(\mathrm{PuOC}) \mathrm{can}$ form biodegradable films, and properties were: film with tensile strength of $68.08 \mathrm{MPa}$ and elongation to break of $36.62 \%$ was produced when $\mathrm{pH}$ was 12 and heating $\mathrm{T} 90^{\circ} \mathrm{C}$ [82].

$\mathrm{PuOC}$ protein isolate (PuOC PI) in preparation of biodegradable films at different $\mathrm{pH}$ values $(2-12)$ and plasticizer content $(0.3-0.6 \mathrm{~g}$ glycerol/g PuOC PI) were produced with 0.4 and $0.5 \mathrm{~g}$ glycerol $/ \mathrm{g}$. The amount of added glycerol significantly affected tensile strength, elongation at break and solubility of the films. Gas permeability of films with $0.4 \mathrm{~g}$ glycerol/g PuOC PI showed that these films represent an excellent barrier for $\mathrm{O}_{2}, \mathrm{~N}_{2}, \mathrm{CO}_{2}$ and air. These films have improved elongation at break and gas permeability characteristics compared to PuOC biodegradable films, thus they could be used as gas barrier stretch coating [83].

Guar-xanthan and pumpkin oil cake (PuOC) can improve the flexibility of polysaccharides films with addition of plasticizer could modify the flexibility of biopolymers. The results showed that guar-xanthan improves and the mechanical properties of PuOC films, but only if the film-forming solution is homogenized with ultra turrax [84]. The influence of glycerol and guar-xanthan in different concentrations on bi-layer film based on pumpkin oil cake (PuOC) and corn zein, and to find optimal concentrations of these additives which result in film with optimal mechanical and barrier characteristic concentrations of glycerol $(30 \%, 40 \%$, and $50 \%)$ as plasticizer and guar-xanthan $(0.1 \%, 0.3 \%$, and $0.5 \%)$ as a stabilizer were added in PuOC layer, with corn zein film. Films showed poor barrier for water vapour, typical for biopolymer-based films, very good barrier to $\mathrm{O}_{2}$, transmission rate of $\mathrm{CO}_{2}$ increased [85]. 


\subsection{Hypothesis and Objectives}

Biopolymers present remarkable characteristics that distinguish them from any other class of compounds and that make them ideal for diverse applications. Its fibrillar nature and its large size result, in short, features that extend at the macroscopic level [86].

Some of these properties are present in polysaccharides, such as the large size of the macromolecules, their size distribution, their architecture, the specific nature of their chemical groups, the arrangement of these groups in the chains and the state of aggregation of the molecules [87].

For this reason, it is important to carry out a series of tests that allow knowing their structure and behavior against external factors, to determine their properties and possible applications [87]. The tests carried out can be divided into two groups: 1) Structural analysis: characterize the internal structure of the material through techniques such as dynamic light scattering, density, viscometry and rheometry [88]. 2) Tests or functional analysis: they address the knowledge of the behavior of the material against agents such as water, gases, the application of a force, etc.

Then, the techniques and materials used in each of them are detailed. In the first place, tests performed with alcayota gum solutions as dynamic light scattering, density, viscometry and rheological characteristics analysis were described in a previous paper [88]. The objective of this work is to produce films from alcayota gum, they were hydrolyzed and modified with glutaraldehyde with the purpose of making them insoluble to water. These films were characterized structurally and functionally in order to elucidate their possible applications.

\section{Experimental}

\subsection{Film Preparation}

Alcayota fruits (Cucurbita ficifolia) of between $3-4 \mathrm{~kg}$ of initial weight were used. The fruit was separated into three parts: husk, pulp, fiber and seeds. The pulp was dried and later ground to obtain the flour from which different determinations will be made.

The grinding time was 10 minutes to $300 \mathrm{rpm}$ in Rolco mill, obtaining particles between 1 and $12 \mu \mathrm{m}$ in diameter. From here on, it will be called Alc to the flour obtained from the grinding of the dried pulp. Aqueous dispersions were prepared at $3 \%$ to $6 \%$ of alcayota meal (Alc). The solutions were stirred magnetically for two hours maintaining a temperature of $65^{\circ} \mathrm{C}$. Agitation and temperature favor the solid-liquid extraction process of the soluble components of the flour. After two hours of agitation, the heating is removed and the stirring continues until the temperature drops to $40^{\circ} \mathrm{C}$.

The temperature should not exceed $80^{\circ} \mathrm{C}$ since undesirable reactions of the polysaccharides present such as thermal hydrolysis browning reactions (Maillard reaction) begin to occur at this temperature. Then, $100 \mathrm{ml}$ of ethanol are added and the mixture is stirred cold for 30 minutes. Subsequently, it is filtered using a 
common plastic filter reserving the precipitate and eliminating the filtrate. The precipitate is redissolved in $100 \mathrm{ml}$ of water. This procedure is carried out several times until the filtrate is translucent. The dispersions obtained were designated Alc(d). Ethanol precipitates the polysaccharides leaving in solution low molecular weight biomolecules, water soluble polyphenols, salts, fats and oils that are eliminated in the filtration and dispersion is purified [89].

The hydrolysis breaks down the polysaccharides into molecules of lower molecular weight. The alkalis can act in reducing terminal units as well as hydroxyl groups. In the first case, the degradation begins at the ends of the chains and advances step by step through the entire chain. In the second case, the hydroxyl groups are substituted, to a degree that depends on the reactivity of the groups and on the nature of the reaction. The hydrolysis can also occur at other sites such as glycosidic linkages, acid groups or ester linkages [90] [91] [92].

The procedure consists in adding to the dispersion $\operatorname{Alc}(\mathrm{d}), 10 \mathrm{ml}$ of $0.1 \mathrm{M}$ sodium hydroxide, stirring at $65^{\circ} \mathrm{C}$ for two hours and then precipitating with ethanol, in the same way as in the previous stage. The precipitate is washed with ethanol twice, obtaining a polysaccharide of average molecular weight having free hydroxyl groups. After the ethanoic washes, the precipitate is redispersed in $100 \mathrm{ml}$ of distilled water. The dispersion obtained was called AlcOH(d). Finally, to dispersion $\mathrm{AlcOH}(\mathrm{d})$ is added $5 \mathrm{ml}$ of glycerol and stirred cold for a few minutes to homogenize.

\section{Film Preparation and Crosslinking}

Once the dispersion of the previous stage was obtained, it was placed in a smooth mold of $13 \mathrm{~cm}$ in diameter and it was placed in an oven at a temperature of $50^{\circ} \mathrm{C}$ for 24 hours. Slow evaporation of the solvent is preferable in order to obtain a dense, pore-free membrane, glycerol is normally added as plasticizer [93]. They were then demolded and placed between two glass plates for 48 hours to avoid deformation of the surface of the membranes. In this last period the solvent is finished evaporating. The films obtained were named AlcOH.

Crosslinking is the process by which dense membranes insoluble in water are obtained, more resistant and less biodegradable. As a result of the crosslinking of the biopolymer, the density of the bonds between the chains increases. In addition, the polymer networks developed by the crosslinking can stop or decrease the migration of contaminants from one side of the film to the other. The increase in the amount of bonds, produces the reduction of the permeability of gases and water vapor and provides greater stability of the membrane at low $\mathrm{pH}$ values.

Glutaraldehyde, are frequently used to crosslink polysaccharides. The molecule has an aldehyde group at each end and a flexible hydrocarbon chain. The molecules are small enough to penetrate tissues and films [94]. Glutaraldehyde is one of the most effective crosslinking agents. The reaction occurs between the carbonyl groups of the crosslinking agent and the hydroxyl groups of the polysaccharide chains [95] [96]. 
The crosslinking technique used was chemical crosslinking. The crosslinking solution was prepared in the following manner: $100 \mathrm{ml}$ of acetone acidified with $1 \mathrm{ml}$ of concentrated $\mathrm{HCl}$ was added in a vessel and then $5 \%$ glutaraldehyde was added. Several membranes were immersed in the solution and kept in shaker (Rolco, Argentina) for 24 hours. The same procedure was performed on other membranes to obtain films with 2, 12 and 24 hours of crosslinking.

Once the selected crosslinking time had been completed, a wash with an ethanol-water solution in a 1:1 ratio was carried out, leaving the membranes submerged in this mixture for 4 hours in shaker to eliminate the reagents. Once this period had elapsed, they were removed from the mixture and brought to an oven at $60^{\circ} \mathrm{C}$ to eliminate the remains of solvents. The films obtained were named, according to the crosslinking time they had, AlcOH-Glu2, AlcOH-Glu12 and AlcOH-Glu24.

\subsection{Film Characterization}

\subsubsection{FTIR}

FTIR spectra were determined using an FTIR Varian 640 Spectrometer using ATR mode. The samples were dried at $60^{\circ} \mathrm{C}$ for $48 \mathrm{~h}$ before performing the measurement. The obtained spectrum had a resolution of $4 \mathrm{~cm}^{-1}$ and consisted of approximately 3500 points with an integration times of $60 \mathrm{~s}$ ( $1 \mathrm{~s}$ per scan). Spectra were scanned between 4000 and $500 \mathrm{~cm}^{-1}$ at ambient temperature. The number of scans for each sample was 64 .

\subsubsection{SEM Images and EDAX Analysis}

Morphology of films was observed using a scanning electron microscope (SEM) LEO 1450VP, and energy dispersion X-ray analysis was carried out using an EDS Genesis 2000 (EDAX). For the SEM morphological surface analysis, samples were prepared by immersion in liquid nitrogen and afterward coated with gold. They were observed under high vacuum and EDAX spectrums were obtained applying an acceleration voltage of $120 \mathrm{kV}$.

\subsubsection{X-Ray Diffraction}

$\mathrm{X}$-ray diffractions $(\mathrm{XRD})$ studies were carried out using an equipment Rigaku model D-Max III C, lamp of $\mathrm{Cu} \mathrm{K}$ and filter of Nickel. The $2 \theta$ operational range was from $0^{\circ}$ to $30^{\circ}$. The d-spacing was determined by Bragg's equation.

$$
n \lambda=2 d \sin \theta
$$

where $d$ is the average intercatenary distance, $n$ is the integer determined, $\lambda$ is the wavelength of the X-ray (nm), and $\theta$ is the Bragg's angle.

\subsubsection{Thermal Analysis}

Thermogravimetric analysis (TGA) was performed to estimate the thermal stability of the alcayota gum films. TGA measurements were recorded on TG 2950 analyzers (TA Instruments, Inc., New Castle, USA), respectively. The operating conditions were as follows: 1) heating rate: $10^{\circ} \mathrm{min}^{-1}$ and, 2) atmosphere: static air or dynamic $\mathrm{N}_{2}(99.99 \%$, flow rate $50 \mathrm{~mL} / \mathrm{min}$, microfiltrate). The thermogra- 
vimetric temperature axes were calibrated with indium (99.99\%, melting point of $\left.156.60^{\circ} \mathrm{C}\right)$ and the Curie point of $\mathrm{Ni}\left(353^{\circ} \mathrm{C}\right)$, respectively. Empty aluminum pans $(40 \mathrm{~mL})$ were used as references. Polysaccharide samples of about $8 \mathrm{mg}$ were employed.

\subsubsection{Solubility Tests}

The study of the solubility of biopolymers in different solvents is important when specifying their resistance to certain environments due to their use in the manufacture of containers, storage containers, etc. The low solubility of the biopolymers used for packaging is one of the most important requirements in food and pharmaceutical applications [97].

Samples of equal size were cut from the films AlcOH-Glu12 and AlcOH-Glu24. In distilled water, distilled water was placed, one sample was immersed per glass and its behavior was observed under various conditions: cold $\left(20^{\circ} \mathrm{C}\right)$, hot $\left(70^{\circ} \mathrm{C}\right)$, static conditions (without agitation) and under dynamic conditions (with agitation).

The Edding ${ }^{\circledR}$ brand 710-711 solvent was written with ink on the samples that were immersed in water to observe the resistance of the same about the written film.

The conditions of high temperature and agitation were achieved using Velp magnetic stirrers with temperature control. The samples were kept submerged for at least 2 hours in each experience. A similar test was carried out, using 10\% $\mathrm{HCl} 0.1 \mathrm{M}$ and $10 \% \mathrm{NaOH} 0.1 \mathrm{M}$ solutions at room temperature by two hours.

\subsubsection{Contact Angle}

The contact angle is a function of the surface tension of the liquid and the surface free energy of the substrate. It can be evaluated by a drop of a pure liquid placed on a solid. The angle formed between the solid/liquid interface and the liquid/vapor interface, whose vertex is where the three interfaces meet, constitutes the contact angle.

The Young equation shown below (Equation (2)) describes the interactions between the adhesion and cohesion forces and from this equation the surface energy per unit area can be determined.

$$
\gamma^{s v}=\gamma^{s l}+\gamma^{l v} \cos \theta
$$

where $\theta$ is the contact angle, $\gamma^{s v}$ is the surface tension of the solid/vapor interphase, $\gamma^{s l}$ is the surface tension of the solid/liquid interface and $\gamma^{v}$ is the surface tension of the liquid/vapor interface.

Process: The films were placed on a smooth surface and $0.1 \mathrm{ml}$ of distilled water was deposited on them. The height $(h)$ of the drops with a Vernier caliber was measured at times: 0,15 minutes, 30 minutes and 60 minutes. The same procedure was performed with solvent ink.

$$
h=h_{1}-h_{0}
$$

where $h_{1}$ is drop height and $h_{0}$ is surface height $(\mathrm{cm})$. 
When the liquid wets and spreads on the surface of the membrane, the contact angle is between $0^{\circ}$ and $90^{\circ}$ and the appropriate ratio is:

$$
\cos \theta=1-\sqrt{\frac{B h^{2}}{1-\frac{B h^{2}}{2}}}
$$

When the liquid does not wet, the contact angle is greater than $90^{\circ}$ and the relationship is:

$$
\cos \theta=-1+\sqrt{\frac{4-2 B h^{2}}{B h^{2}}}
$$

where $B=\rho g / 2 \gamma$, being $g$, the acceleration of gravity $\left(980 \mathrm{~cm} / \mathrm{s}^{2}\right), \rho$, density and $\gamma$, the interfacial tension. Table 1 summarizes these properties for distilled water and solvent ink.

\subsubsection{Water Sorption}

The water sorption measures measure the degree of swelling of the membrane when in direct contact with water. From these measurements you have an idea of the mechanical stability of the materials.

The importance of these measures lies in the need to know the behavior of the material in case it is used as a package, comes in occasional contact with water or is used to package wet or watery foods. It is also important to evaluate the behavior of the polymer against water as this is the agent present at the time of biodegradation of the material [98].

Two techniques were used to measure the degree of swelling of the membranes: Swelling Index and Water Absorption, better known by their English names, Swelling Index and Water Up take, respectively.

Swelling Index uses the measurement of the weight of the samples submerged in a bath of distilled water. For its part, Water Up take (WU) uses the measure of the thickness and the characteristic length of the samples. As time progresses, the degree of swelling increases, which is reflected in the increase in thickness, length and weight until equilibrium is reached. By increasing the hydrophobicity of the film, the time necessary to reach equilibrium is less. Generally, the same samples are used to perform these two tests simultaneously.

Process: Samples of $30 \mathrm{~mm}$ diameter were cut, measured with Vernier caliber, weighed in analytical balance and their thickness was measured with Koffer micrometer of precision \pm 1 micrometer. The samples were immersed in Petri dishes with distilled water at room temperature and the diameter $D(\mathrm{~mm})$, the

Table 1. Density and surface tension of distilled water and solvent ink.

\begin{tabular}{ccc}
\hline Properties & Water & Ink \\
\hline$\rho\left(\mathrm{g} / \mathrm{cm}^{3}\right)$ & 0.9971 & $0.90^{\mathrm{a}}$ \\
$\gamma\left(\mathrm{g} / \mathrm{s}^{2}\right)$ & 71.97 & $22.75^{\mathrm{b}}$ \\
\hline
\end{tabular}

${ }^{\mathrm{a}}$ Edding 711, black color, 2009. http://www.edding.com.ar/productos_edding_marcadores_permanentes.html; bhttps://www.flexografia.com/blank-k4ris 
thickness $E(\mu \mathrm{m})$ and the weight $P(\mathrm{~g})$ of each of the samples were measured every 10 minutes until equilibrium was reached. The subscript " 0 " indicates the initial measurement of each one.

The data obtained from the Swelling Index test were used to calculate the amount of water sorbed:

$$
S_{i}(\%)=\left(P / P_{0}-1\right) \cdot 100
$$

$S_{i}(\%)$ versus time was plotted.

With the data of Water Up take, parameters analogous to Si are calculated:

$$
\begin{aligned}
W U_{\text {diam }}(\%) & =\left(D / D_{0}-1\right) \cdot 100 \\
W U_{\text {esp }}(\%) & =\left(E / E_{0}-1\right) \cdot 100
\end{aligned}
$$

The subscripts "diam" and "es" are referred to diameter and thickness, respectively.

\subsubsection{Barrier Properties}

In contrast to glass or metal as packaging materials, containers made of plastic are permeable, in different degrees, to small molecules such as gases, water vapor, organic vapors and other low molecular weight molecules such as flavors, aromas and additives present in food. As a consequence of the barrier properties of the materials, the permeability of these varies in a wide range.

The permeation of a gas through the polymer is described by a diffusion model, using the Henry and Fick Laws to obtain the expression representing the permeation rate taking into account the area and thickness of the film.

The mechanism can be described for a homogeneous polymer film of thickness 1 , permeant pressure $p$ (with $p_{1}>p_{2}$ ) and $\mathrm{c}$ as permeant concentrations through the film (with $c_{1}>c_{2}$ ).

$$
\begin{gathered}
T=Q /(A \cdot t) \\
P=T \cdot \lambda / \Delta P[=](\mathrm{ng} \cdot \mathrm{m}) /\left(\mathrm{m}^{2} \cdot \mathrm{s} \cdot \mathrm{Pa}\right)
\end{gathered}
$$

where $T$ is the transmission speed ( $\left.\mathrm{ng} / \mathrm{m}^{2} \mathrm{~s}\right) ; Q$, the permeating mass (ng); $\lambda$, the thickness of the film (m); $A$, the area of the cell $\left(\mathrm{m}^{2}\right) ; t$, the measurement time (s) and $\Delta P$, the pure water vapor pressure, in the case of calculating water vapor permeability $(4238.605 \mathrm{~Pa})$, or high pressure in the case of calculating gas permeation.

Water vapor permeability. The ASTM E96 standard defines the water vapor permeability as the rate of water vapor transmission through a unit area of a flat material and per unit thickness induced by a unitary vapor pressure difference between the two surfaces of the material under study, under certain temperature and humidity conditions [99].

Experiences of water vapor permeation were performed inside an automatic model 514 humidity and temperature controller that consists of a humidity sensor and a temperature sensor with their corresponding control units. The humidity and temperature sensors are included inside a hermetically closed chamber. 
The humidity sensor provides an immediate response, in a range of relative humidity from 0 to $100 \%$. Accuracy in the measurement is $\pm 2 \%$ when the relative humidity goes from 0 to $90 \%$ and $\pm 3 \%$ above $90 \%$ at $20^{\circ} \mathrm{C}$. The temperature sensor provides an immediate response in the range of 0 to $40^{\circ} \mathrm{C}$, with an accuracy of $\pm 2^{\circ} \mathrm{C}$. The humidity control unit monitors the humidity values inside the chamber by activating or deactivating a humidifier in order to maintain the relative humidity inside the chamber at the desired values. In the same way, the temperature controller operates by turning a light bulb on or off to keep the temperature at the desired values.

For the experience, glass cells with a perforated lid were used, in which the sample is placed. A precision Radwag (Poland) analytical balance was also used $\pm 0.1 \mathrm{mg}$.

Process. $16 \mathrm{~g}$ of silica gel ( $0 \%$ relative humidity) were weighed in each of the cells, and samples of known thickness and diameter were placed on the covers. The cells were closed and the initial weight of them was taken using an analytical balance. They were then placed inside the hermetically sealed chamber at a temperature of $30^{\circ} \mathrm{C}$ and relative humidity of $90 \%$.

The pressure gradient on both sides of the membrane provides the driving force for the vapor to pass through the film. This vapor is absorbed by the silica, so that, as time goes by, the weight of the cells increases. This is recorded, measuring the weight of the cells every 30 minutes during the first hours and then every hour until the silica is saturated, that is until the weight of the cells remains constant. Equations ((9) and (10)) are applied to calculate the permeability values.

Gas permeation: As described above, knowing the gas permeation properties of the films under study is fundamental when it comes to characterizing them. The permeation coefficient $(P)$ was measured to oxygen, nitrogen and carbon dioxide, as well as permeoselectivities.

The permeoselectivity of the films or theoretical separation factors $(\alpha)$ are calculated from the relationship between the permeation coefficients of pure gases such as:

$$
\alpha=P_{i} / P_{j}
$$

Process: Circular specimens were cut from the polymeric films whose effective area was $11.34 \mathrm{~cm}^{2}$ and were placed in the permeation cell (CP). Subsequently, the "degassing" process was applied, consisting of subjecting the membrane to high vacuum conditions ( $p \approx 10^{-4}$ torr) and temperature $\left(30^{\circ} \mathrm{C}\right)$ for 3 or 4 hours. After performing the vacuum, the permeation measurements were carried out using a constant permeate volume of $35.37 \mathrm{~cm}^{3}$ of $\mathrm{O}_{2}$ of the Air Liquid Argentina brand with a purity of $99.9 \%$. Then it was done with $\mathrm{CO}_{2}$ and $\mathrm{N}_{2}$.

The technique of "delay time" consists of measuring the amount of gas that passes through the membrane at time $t$, that is, measure the variation of pressure on the low side $\left(p_{2}\right)$ with time $(t)$, at constant volume $\left(V_{2}\right)$, until this variation becomes constant (steady state). In reality, there is always a non-stationary state, 
because although the high pressure remains constant, the low pressure varies permanently throughout the experience. However, because the low pressure is much lower than the high pressure $(1 \%-2 \%)$ and its variation is so small, it can be considered that the average driving force of the system remains constant throughout the experience and that a Stationary pseudo state is reached. The low pressure was recorded as a function of time in the data acquisition and then graphed to obtain curves. The coefficient of permeability $(P)$ is obtained by applying Equation (12), once the pseudo stationary state has been reached.

$$
P=\left(B l / T_{c} p_{1}\right) \mathrm{d} p_{2} / \mathrm{d} t
$$

where: $P$ is the coefficient of permeability [=] Sweep $=10^{-10} \mathrm{~cm}^{3}$ (STP) $\mathrm{cm} / \mathrm{cm}^{2} \mathrm{~s}$ cmHg; $B=11.53 \mathrm{~cm}^{3}$ (STP) $\mathrm{K} /\left(\mathrm{cm}^{2} \mathrm{cmHg}\right.$ ), is the cell constant; $p_{1}=10 \mathrm{~kg} / \mathrm{cm}^{2}$ or $735.56 \mathrm{cmHg}$, is the pressure on the high pressure side; $T_{c}[=] \mathrm{K}$, is the temperature of the cell; $1[=] \mathrm{cm}$, is the membrane thickness; $\mathrm{d} p_{2} / \mathrm{d} t[=] \mathrm{cmHg} / \mathrm{s}$, is the slope of the linear zone (steady state) in the graph of $p_{2}$ vs $t$. The linear regression of $p_{2}$ vs $t$ allows to determine the time elapsed until reaching the steady state conditions. This "delay time" value $\left(t_{r}\right)$ can be evaluated from the abscissa axis to $p_{2}=0$. Equation 11 was applied to calculate the permeoselectivities.

\subsubsection{Mechanical Properties}

The mechanical properties of a material describe the way in which it responds to the application of a force or load. The force, which acts on the unitary area, generates a deformation. In many materials, elastic stress and deformation follow a linear law. The slope in the linear portion of the strain versus strain curve defines the Young's modulus or modulus of elasticity of a material. Tension tests are used to obtain this and other parameters that represent the mechanical behavior of the material under study.

The modulus of elasticity or Young's modulus (E), is the slope of the stress-strain curve in the elastic region (linear portion of the curve). This relationship is known as Hooke's Law:

$$
E=\sigma / \varepsilon[=] \mathrm{Pa}
$$

where:

$$
\begin{gathered}
\sigma=F / A_{0}[=] \mathrm{N} / \mathrm{m}^{2}=\mathrm{Pa} \\
\varepsilon=\Delta L / L_{0}[=] \mathrm{cm} / \mathrm{cm}
\end{gathered}
$$

where $F$ is the applied force, $A_{0}$ is the initial cross-sectional area, $\Delta L$ is the length change and $L_{0}$ the initial length of the samples.

We used a "Comten Industries" 94 Series CV that has two jaws, the lower fixed and the upper mobile, in which the sample is adjusted. The equipment presents a speed selector of the upper jaw and a controller in which the applied force and the deformation generated as the test is being carried out is observed.

Process. The tests, carried out in triplicate, were carried out at a temperature of $25^{\circ} \mathrm{C}$ and at a relative humidity of $40 \%$. Test pieces $40 \mathrm{~mm}$ long by $10 \mathrm{~mm}$ wide were cut and the thicknesses were measured using a Koffer micrometer 
(precision $\pm 1 \mu \mathrm{m}$ ). Samples were placed in the jaws, separated by a distance of $20 \mathrm{~mm}$. Once the specimens were adjusted to the jaws, the traction was started at a constant speed of $5 \mathrm{~mm} / \mathrm{min}$. The data of force $(F)$ and deformation $(\Delta L)$ were recorded until the rupture of the specimens. These values were transformed to stress $(\sigma)$ and unit strain $(\varepsilon)$, respectively.

With these values, stress versus unitary deformation was graphed, obtaining a curve from which the values of stress to stress, modulus of elasticity and percentage of elongation are determined.

\subsubsection{Colorimetry}

Color is a mental response to the stimulus produced in the retina by visible light radiation, but the measure of this stimulus depends on the conditions that surround it. In order to unify these measures, standard conditions have been defined that allow obtaining comparable results, such as: the observer, the illuminant, the lighting-observation geometry and the measurement interval.

The equipment used was MiniScan EZ colorimeter model MSEZ-4500L with illuminant D65, observer $10^{\circ}$ and geometry $45^{\circ} / 0^{\circ}$. The equipment allows measurements of color index and opacity, the values obtained by the equipment are given in the coordinates of the CIELAB color space.

Process: The color measurements were made on each film with the intermediate viewing area accessory (diameter of $2.5 \mathrm{~cm}$ ). Three measurements were taken at different points of the samples, the average values of these measurements were recorded as the color parameters $\mathrm{L}^{*}, \mathrm{a}^{*}$ and $\mathrm{b}^{*}$. Opacity measurements were also made on the same films.

\subsubsection{Biodegradability}

Biodegradation is the transformation and deterioration that occurs in the polymer due to the action of enzymes and/or microorganisms such as bacteria, yeasts, fungi and algae. The biodegradation can be partial or total. Partial biodegradation consists in the alteration of the chemical structure of the material and the loss of specific properties. On the other hand, in total biodegradation the material is completely degraded by the action of microorganisms with the production of $\mathrm{CO}_{2}$ (under aerobic conditions) and methane (under anaerobic conditions), water, mineral salts and biomass.

Process: Approximately $1 \mathrm{~kg}$ of humidified soil sample (85\% RH) was placed in a covered container. Samples $10 \mathrm{~mm}$ wide by $40 \mathrm{~mm}$ long were cut and buried $2 \mathrm{~cm}$ deep. The closed system was brought to a temperature controlled oven of $30^{\circ} \mathrm{C}$ (mesophilic conditions). The weight and size of the samples were monitored periodically over a 40-day incubation period.

\subsubsection{Sensory Tests}

One of the main requirements when selecting a material for packaging food is that it does not suffer alterations in its organoleptic characteristics, either by migration of certain components present in the same package or because the material is permeable to compounds that affect the food. 
In all cases, the sensory tests are carried out through the participation of judges, who are the people who carry out the evaluations of the samples. These judges may be trained and qualified, such as those required to carry out discriminative, descriptive or scale tests, or they may not be trained (consumers), as in the case of hedonic tests [100] [101].

Due to the relatively low water vapor permeability of the films, it was decided to pack a highly hygroscopic dry food such as commercial common sugar (Ledesma, Argentina). On the other hand, a greater carbon dioxide permeability than oxygen was obtained, which would allow the preservation of foods containing fats without oxidation of the same. To check this last, whole milk powder was selected (whole milk: La Lechera, Argentina). The tests were then focused on observing the humidification (through the formation of aggregates) of the samples in both foods and detecting the oxidation of fats in the case of milk powder.

Process. The packaging was made in glass cells with a perforated lid in which the film was placed. The cells were filled with food and brought to a stove at $30^{\circ} \mathrm{C}$. Sensory tests were performed every 7 days for a month and a half. In the tests, the color, appearance, taste and aroma of all the samples were checked by comparing these parameters with a control sample.

\section{Results and Discussions}

It is always intended to relate the behavior with the structure to try to establish generalizations that facilitate the understanding and prediction of the behavior of the materials. The properties of polymeric materials are responsible for their use instead of other materials and in some cases they have unique properties that make them irreplaceable for certain applications [102].

In the evaluation of the behavior of the material, it is intended to understand the structure-property relationships, as well as to compare the performance and characteristics of one product with another. In the case of the development of new products, the understanding of the structure-property relationship allows controlling their behavior and making decisions related to the development process that will be followed. This knowledge is crucial to facilitate the design of the material and to predict how the product will behave in real service conditions. The comparison between materials is essential in the exploration of opportunities to replace existing products [103].

\subsection{FTIR}

The broadly stretched intense at $3347-3504 \mathrm{~cm}^{-1}$ was due to the associated water besides the hydroxyl stretching vibration of the polysaccharide, so is the vibration at $2927 \mathrm{~cm}^{-1}$ which indicated $\mathrm{C}-\mathrm{H}$ stretching vibration (Figure 1). As for the polysaccharides crosslinked with glutaraldehyde, it can be observed in the IR spectra that the $-\mathrm{OH}$ signal decreases with the increase of the exposure time to $\mathrm{Glu}$, a very characteristic situation of crosslinks where the $-\mathrm{OH}$ groups are replaced by C-O-C groups. 
Three strong absorption bands at $1041-1058 \mathrm{~cm}^{-1}$ in the range of $1200-1000$ $\mathrm{cm}^{-1}$ indicated that the monosaccharide in alcayota gum film had a pyranose ring, as stretching vibrations of $\mathrm{C}-\mathrm{O}-\mathrm{H}$ side groups, and $\mathrm{C}-\mathrm{O}-\mathrm{C}$ glycosidic band vibrations [104]. At the higher hydration level there was only one dominant band at $1041-1047 \mathrm{~cm}^{-1}$ from glucan [105], but at lower hydration the mannan band at $1058 \mathrm{~cm}^{-1}$ was also visible [106]. The relatively strong absorption peak at $1614-1625 \mathrm{~cm}^{-1}$ was also due to the associated water. The signals at 1620 and $1415 \mathrm{~cm}^{-1}$ designated the asymmetric and symmetric stretching of carboxylate anions group $(\mathrm{C}=\mathrm{O})$ [107]. The absorption at $923 \mathrm{~cm}^{-1}$ suggested the existence of $\beta$-glycopyranosidic linkages [108] [109] [110] [111] while the absorption at $833 \mathrm{~cm}^{-1}$ indicated that the polysaccharide had $\alpha$-configurations in it [112]. Finally, signals at $806 \mathrm{~cm}^{-1}$ and stand for mannose residues [113] (Figure 2).

\subsection{X-Ray Diffraction}

Neat and crosslinked AlcOH films were structurally studied through X-ray analysis. Although polymers in general show amorphous X-ray patterns, structural modifications such as crosslinking may be seen through shifting and narrowing of typical broad bands. Bragg's equation is used to estimate an inter-chain distance

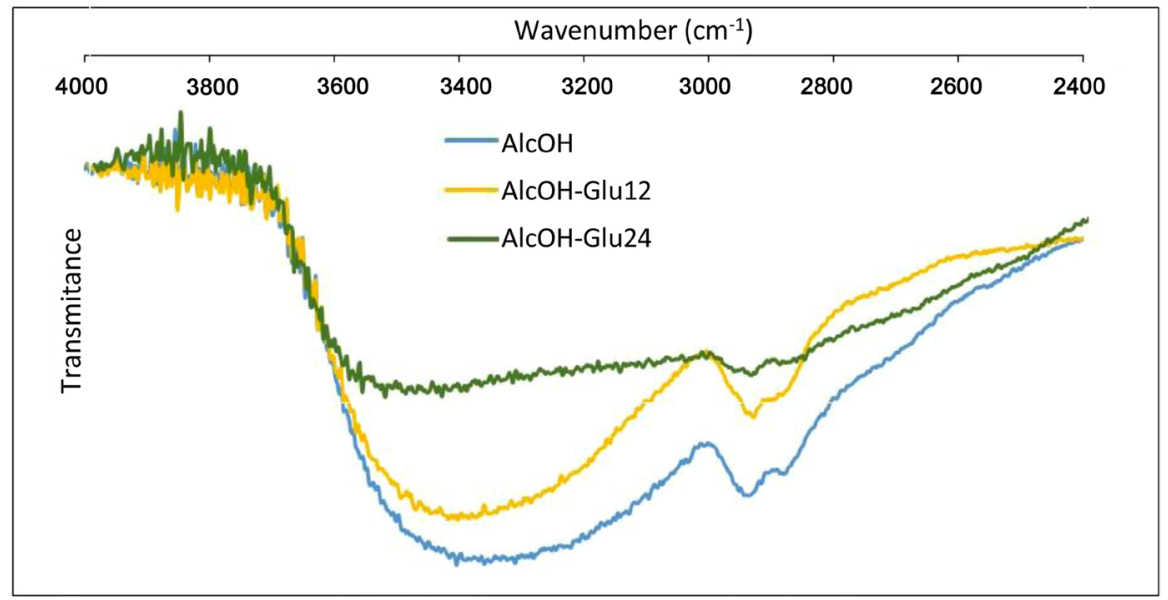

Figure 1. FTIR-ATR of films, range $2400-4000 \mathrm{~cm}^{-1}$.

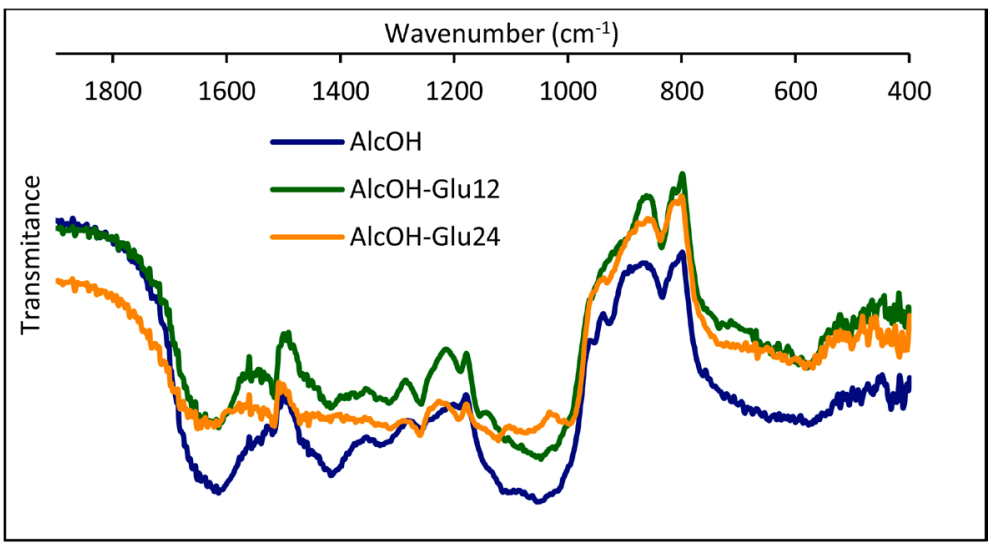

Figure 2. FTIR-ATR of films, range $400-2000 \mathrm{~cm}^{-1}$. 
known as d-spacing. This parameter gives an idea about the spacing between two adjacent polymer chains within the polymer matrix. The d-spacing is obtained from the Bragg's equation as the " $\mathrm{d}_{\text {spacing }}$ " value taking the $2 \theta$ angle from the maximum of the broad band. To analyze structural changes in Alcayota gum films, X-ray diffraction patterns of the films with different crosslinking times were studied and they are shown in Figure 3.

Hydrolyzed Alcayota gum (AlcOH) showed an amorphous XRD pattern and the scattering angle $(\theta)$ was observed at $10.725^{\circ}$ and $8.225^{\circ}$ which correspond to $\mathrm{a} \mathrm{d}_{\text {spacing }}$ of $4.14 \AA ̊$ and $5.38 \AA \AA$. Modified biopolymers AlcOH-Glu12 and AlcOH-Glu24 also showed amorphous X-ray patterns, besides, they showed broader bands with respect to neat $\mathrm{AlcOH}$. These results indicate that crosslinking modified the original molecular arrange of $\mathrm{AlcOH}$, becoming a less crystalline polymer as the time of crosslinking increases. AlcOH-Glu12 showed $\theta$ angles at $10.70^{\circ}$ and $7.825^{\circ}$, corresponding to $\mathrm{d}_{\text {spacing }}$ values of AlcOH-Glu12 $=4.15 \AA$ and $5.65 \AA$, respectively. And AlcOH-Glu24 showed $\theta$ angles at $11.075^{\circ}$ and $7.850^{\circ}$, corresponding to $\mathrm{d}_{\text {spacing }}$ values of $4.01 \AA$ and $5.64 \AA$, respectively (see Table 2 ). The increase in inter-chain distance as the crosslinking time increases is a way of proving the crosslinking efficiency. Besides, the increase in $\mathrm{d}_{\text {spacing }}$ is attributed to

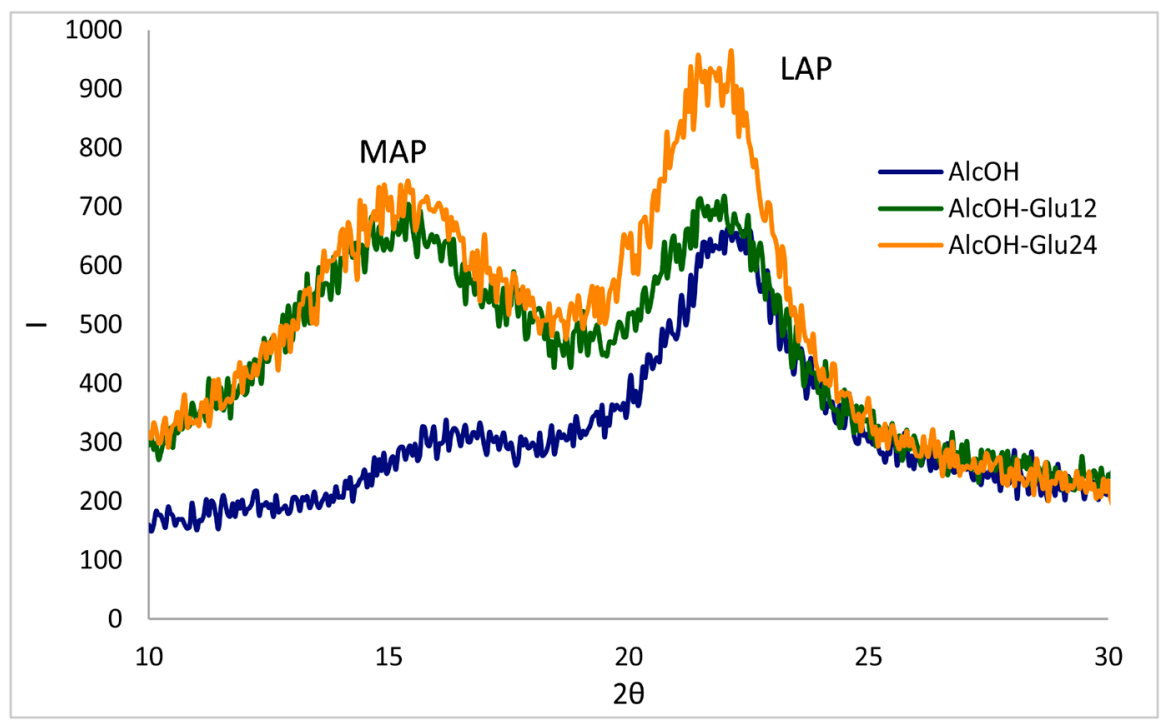

Figure 3. XRD of films.

Table 2. Contact angle and $\mathrm{d}_{\text {spacing }}$ of films.

\begin{tabular}{ccccc}
\hline & $\begin{array}{c}\text { less amorphous } \\
\text { peak }\end{array}$ & $\begin{array}{c}\text { more amorphous } \\
\text { peak }\end{array}$ & $\begin{array}{c}\text { less amorphous } \\
\text { peak }\end{array}$ & $\begin{array}{c}\text { more amorphous } \\
\text { peak }\end{array}$ \\
\hline Membrane & $\theta$ & $\theta$ & $\mathrm{d}_{\text {spacing }} \AA$ & $\mathrm{d}_{\text {spacing }} \AA$ \\
AlcOH & 10.725 & 8.225 & 4.14 & 5.38 \\
AlcOH-Glu12 & 10.700 & 7.825 & 4.15 & 5.65 \\
AlcOH-Glu24 & 11.075 & 7.850 & 4.01 & 5.64 \\
\hline
\end{tabular}


the molecular size of crosslinking agent, i.e. glutaraldehyde, which is placed between two adjacent polymer chains, spacing them [114] [115]. Crosslinking reactions caused structural changes in the macromolecular arrangement of polysaccharide chains, sometimes called "interruptions". These interruptions can dimensional arrangement known as tertiary structure [96]-[116]. Diffraction patterns of AlcOH-Glu12 and AlcOH-Glu24 depicted the influence of crosslinking by increasing broadness of amorphous bands. This result can be associated with the secondary structure modification. This confirms that glutaraldehyde prevents molecular packing of polysaccharide chains by rigidizing polymeric matrix [116].

Although both peaks are amorphous, see Table 2, one of them is more amorphous (MAP) and the other is less amorphous (LAP), mainly in the crosslinked films. The LAP presents a $\mathrm{d}_{\text {spacing }} \approx 4 \AA$ that is to say with distances between chains narrower than the MAP with a $\mathrm{d}_{\text {spacing }}>5 \AA$. This can be explained due to two inter-chain relationships from two types of unions that are manifested by X-Ray Diffraction. This phenomenon is based on the fact that the intercatanarian union originates in a main chain, and the other union is generated in a side chain of a macromolecule with branching. A situation, at least rare, is that in the LAP zone, there is an increase in the band area, possibly caused by the crosslinking with glutaraldehyde, and this increase in area increases with the increase in the time of exposure to glutaraldehyde.

\subsection{Thermogravimetric Analysis}

Thermogravimetric (TGA) measurements were carried out in order to better assess the thermal behavior of biopolymeric films. Neat Acayota Gum and 12 and 24 hs crosslinked Alcayota Gum films were evaluated. Results are illustrated in Figure 4. TGA experiments show two events of mass loss for both biopolymer

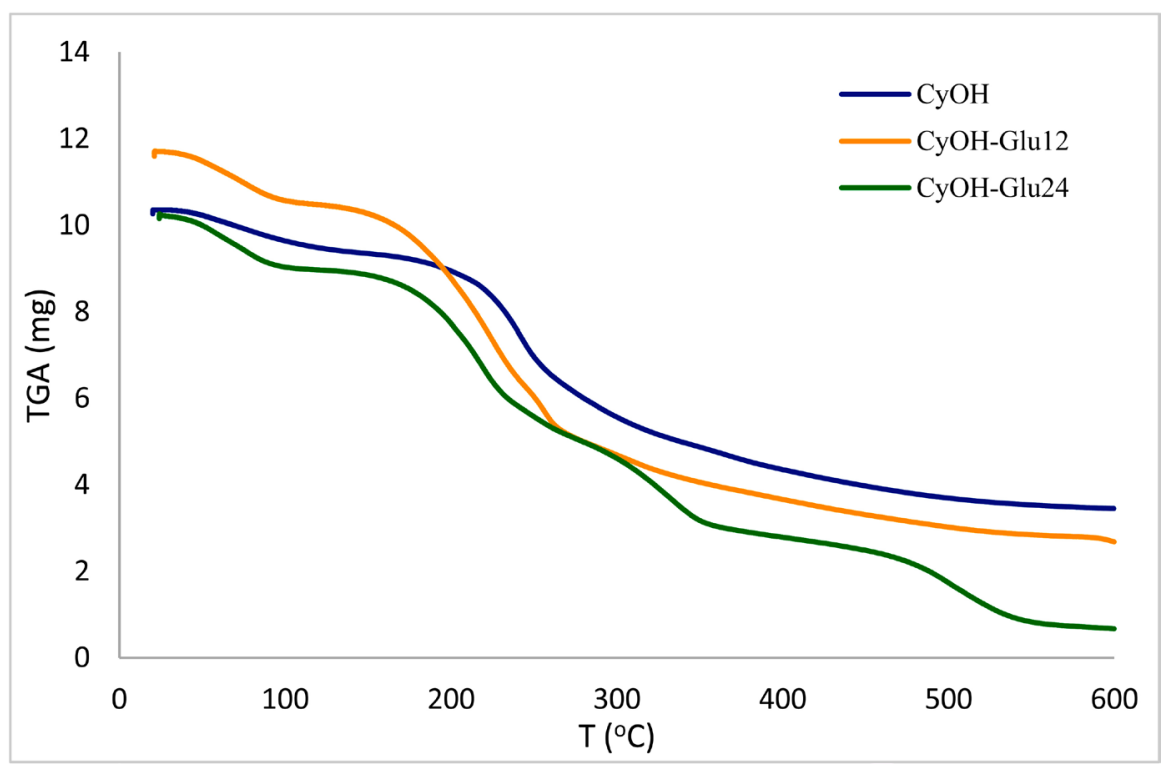

Figure 4. TGA of films. 
films, being the first step near to $100^{\circ} \mathrm{C}$ and is attributed to the loss of adsorbed and structural water of biopolymers [117]. AlcOH film shows a second mass loss event at $251^{\circ} \mathrm{C}$ resulted in a weight loss of approximately $70 \%$ attributed to the polysaccharide decomposition. On the other hand, AlcOH-Glu12 shows a second mass loss at about $240^{\circ} \mathrm{C}$ corresponding to $5 \%$ of weight loss, following by a higher mass loss at $267^{\circ} \mathrm{C}$ attributed to the starting crosslinking break down, with $15 \%$ mass loss. The $5 \%$ mass loss was associated to the entrapped water molecules within crosslinked $\mathrm{AlcOH}$ matrix. Finally, total decomposition of AlcOH-Glu12 was observed at around $500^{\circ} \mathrm{C}$, indicating a higher thermal resistance of the crosslinked polymer regarding to the neat AlcOH film [118] [119] [120] [121] [122]. Finally, AlcOH-Glu24 shows a second mass loss at about $232^{\circ} \mathrm{C}$ corresponding to $10 \%$ of weight loss, following by a higher mass loss of $10 \%$ at $354^{\circ} \mathrm{C}$ attributed to the starting crosslinking break down. The $10 \%$ mass loss was associated to the entrapped water molecules within crosslinked AlcOH matrix. Finally, total decomposition of AlcOH-Glu24 was observed at around $500^{\circ} \mathrm{C}$.

\subsection{Scanning Electron Microscopy}

In order to know the surface morphology of the obtained films, SEM images of the films AlcOH, AlcOH-Glu12 and AlcOH-Glu24 were obtained.

In the film $\mathrm{AlcOH}$, which does not present crosslinking, a smooth and dense surface is observed with some particles protruding on the surface (Figure 5). The crosslinked films lose this superficial softness and a much rougher surface is observed due to the appearance of new bonds between the molecules by the crosslinking agent [123].

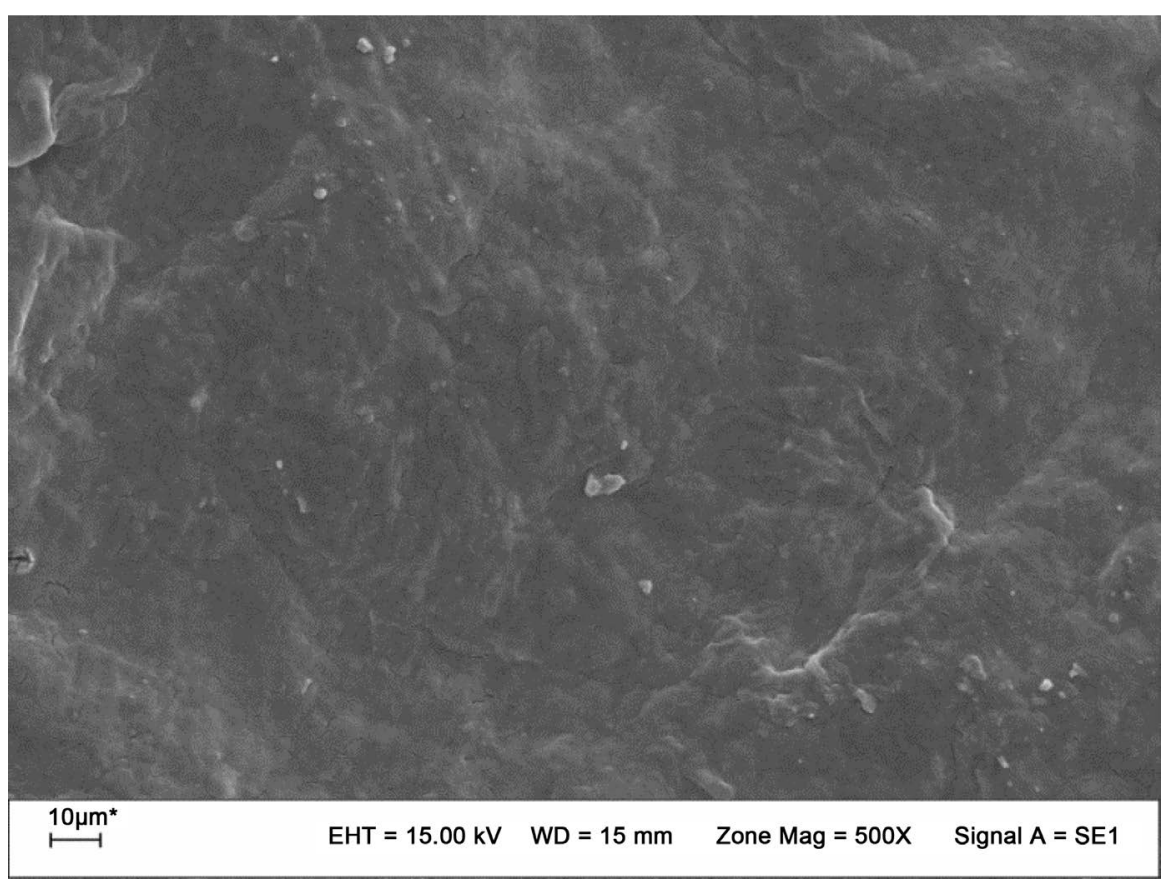

Figure 5. SEM 500× image of the AlcOH film. 
Comparing Figure 6 and Figure 7, it is observed that the image of the film AlcOH-Glu24 presents less roughness than the AlcOH-Glu12 because the large number of bonds formed in the longer crosslinking, generate a very dense network of polysaccharides that consolidates the surface. Also, compared to Figure 5 it can be seen that this is much less rough than the crosslinked films.

The SEM image were taken to $7000 \times$ of the films to observe the particles in

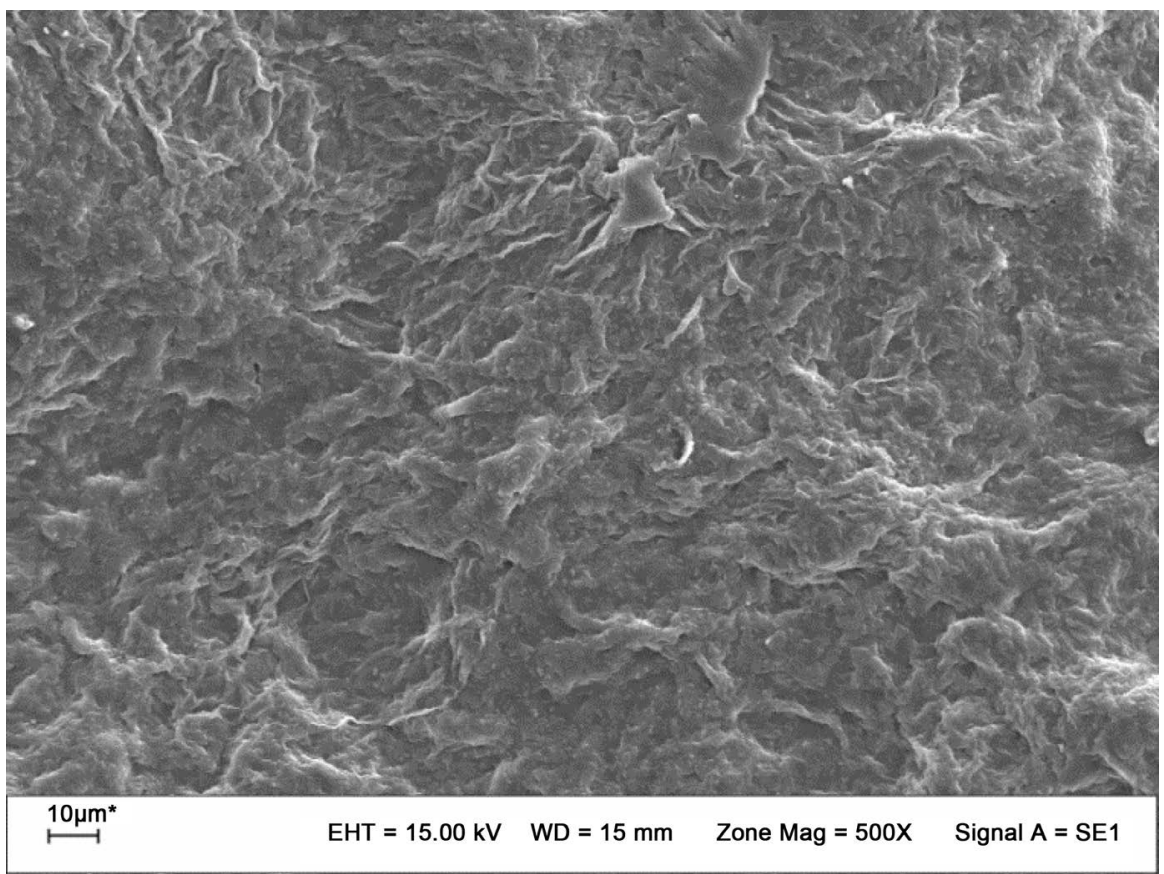

Figure 6. SEM 500× image of the AlcOH-Glu12 film.

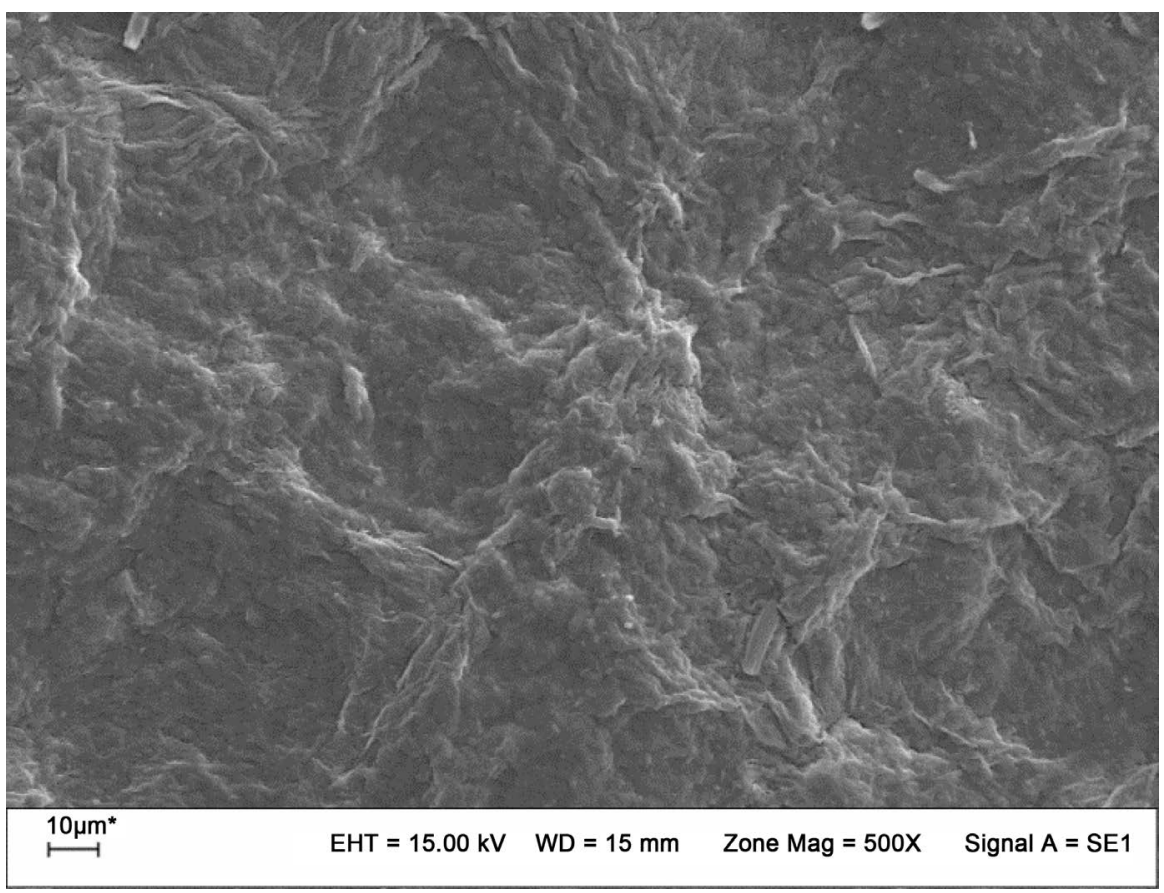

Figure 7. SEM 500× image of the AlcOH-Glu24 film. 
the matrix, these were rod-like, as shown in the images, and a size of $1.012 \times$ $1.688 \mu \mathrm{m}$. Due to the similarity with the bacilli bacterial, an elemental analysis was carried out on the particles and on the matrix to corroborate that it was not bacterial contamination. Due to the absence, in the elemental analyzes, of compounds such as nitrogen, sulfur and phosphorus (characteristic elements of the microbial presence), it is concluded that the films did not suffer microbiological contamination and the particles observed correspond effectively to the polysaccharide. In Figure 8 and Figure 9 the SEM 7000x images of the AlcOH and AlcOH-Glu12 films are presented together with their respective elementary analyzes.

Due to the absence, in the elemental analyzes, of compounds such as nitrogen,

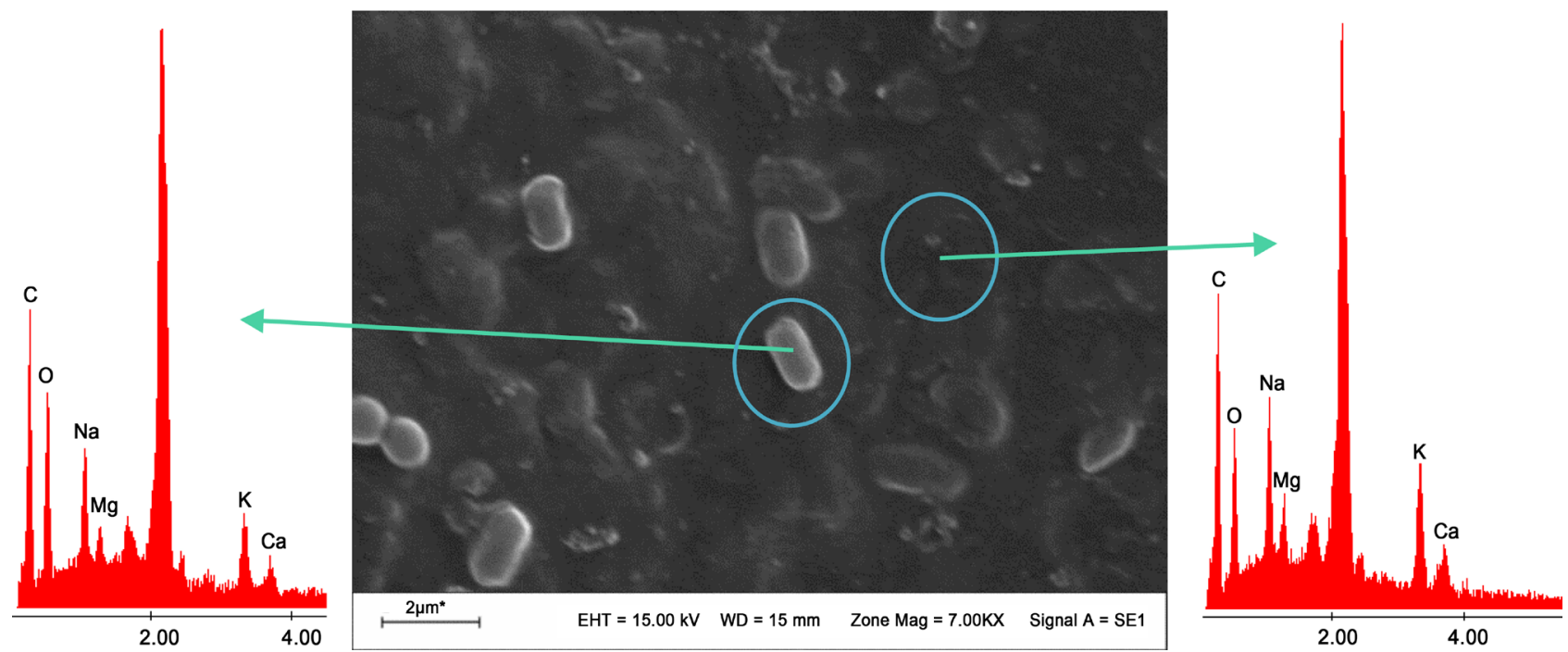

Figure 8. SEM 7000× image of the AlcOH film next to the elemental analysis of the particle and the matrix.

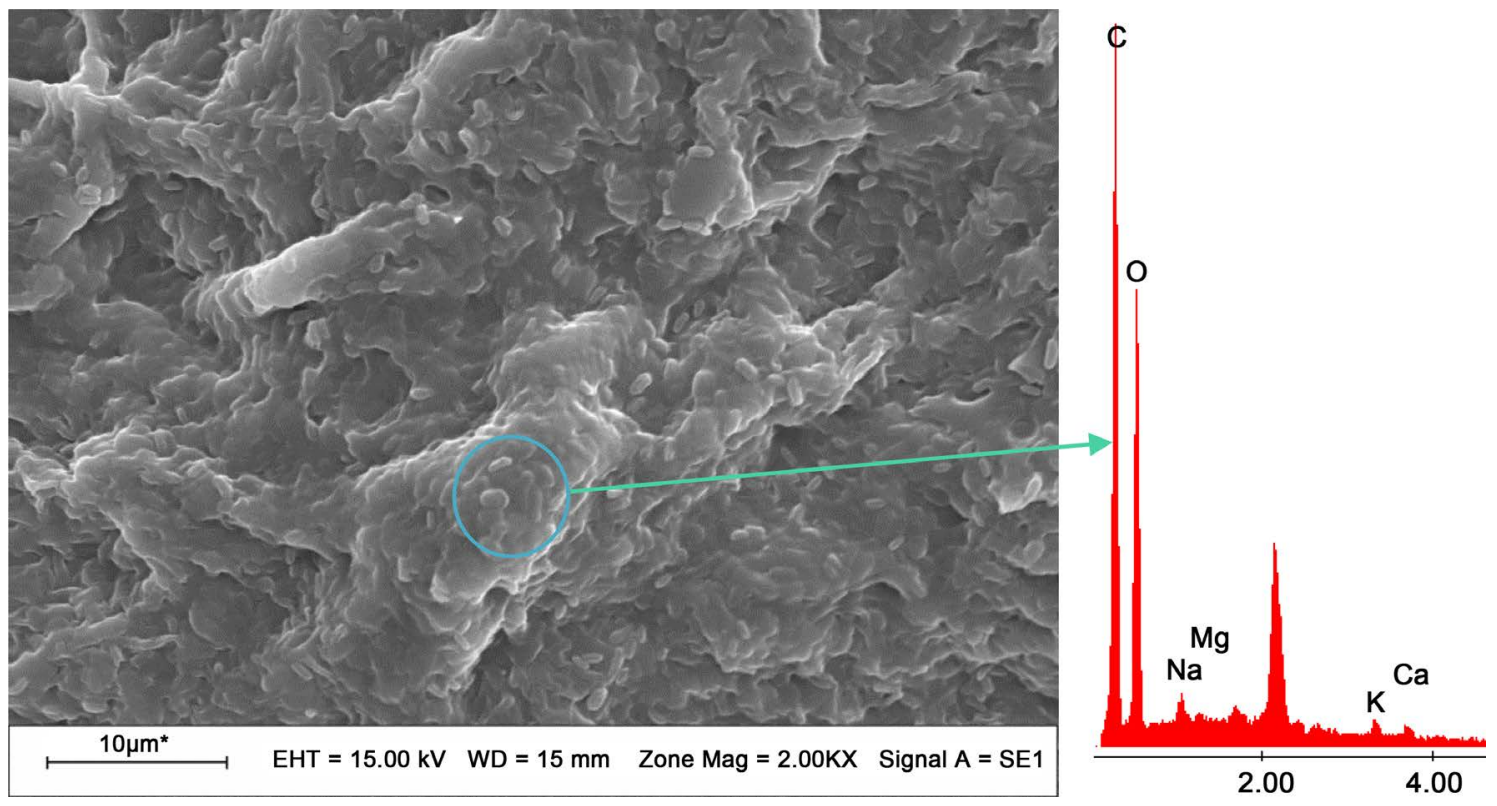

Figure 9. SEM image to $7000 \times$ of the AlcOH-Glu12 film next to the elemental analysis of the particle. 
sulfur and phosphorus (characteristic elements of the microbial presence), it is concluded that the films did not suffer microbiological contamination and the particles observed correspond effectively to the polysaccharide.

Comparing Figure 8 and Figure 9, one can observe the increase in the intensity of the carbon and oxygen peaks produced by crosslinking with glutaraldehyde. A decrease in the content of alkali and alkaline earth metals was also observed because in the crosslinking process $\mathrm{HCl}(\mathrm{c})$ is used, the chloride anions compete for these metals and are removed from the polymeric matrix in the ethanoic washings that are carried out afterwards of crosslinking.

\subsection{Solubility Tests}

The samples subjected to this test correspond to the membranes with 12 and 24 hours of crosslinking (AlcOH-Glu12 and AlcOH-Glu24). In the tests carried out, distilled water was used as a solvent. The tests were carried out first under static and cold conditions. When not observing changes in the structure of the submerged samples, the agitation was initiated to verify its mechanical resistance. After two hours, it began to warm up without removing the agitation. First the temperature was raised to $40^{\circ} \mathrm{C}$ and it was kept at this temperature for two hours. Without finding changes, the temperature was again increased to $70^{\circ} \mathrm{C}$ and remained in these conditions for the same period of time.

At $84^{\circ} \mathrm{C}$, small bubbles of water began to be observed in the AlcOH-Glu12 film. Possibly this is due to the entry of solvent in those areas where the amount of links formed by crosslinking is lower.

Finally, the temperature was raised to $94^{\circ} \mathrm{C}$ and maintained for another two hours. At the end of the experience, no changes were observed in the film Al$\mathrm{cOH}-\mathrm{Glu} 24$. While in the AlcOH-Glu12 the same bubbles that appeared at $84{ }^{\circ} \mathrm{C}$ were observed, however, they did not increase in size or quantity. Once the two hours were finished, the samples were allowed to dry, observing the disappearance of the bubbles of the AlcOH-Glu12 film.

In both films a slight swelling produced by the absorption of solvent was observed for the case when the solution is at $84^{\circ} \mathrm{C}$ without losing mechanical stability.

In the case of AlcOH membranes, they lose their mechanical stability in a water bath, as reported for pumpkin oil cake [81] [82] [83] [84] [85].

The inks used did not change, being able to conclude that the films can be printed obtaining water resistant images.

In Figure 10 the films are shown at the end of the experience. The image on the left corresponds to the film AlcOH-Glu24 and the one on the right to the film AlcOH-Glu12.

The samples submerged in the $\mathrm{HCl}$ and $\mathrm{NaOH}$ solutions showed no visible changes, concluding that the crosslinked membranes are also resistant to slightly acidic or basic media at room temperature in both static and dynamic conditions. 


\subsection{Contact Angle}

Wettability studies usually involve contact angle measurement as a primary datum, which indicates the degree of wettability when a solid and liquid come into contact. Small contact angles (less than $90^{\circ}$ ) correspond to materials with high wettability, while large contact angles (greater than $90^{\circ}$ ) correspond to materials with low wettability.

It should be noted that at initial times the contact angle is greater than 90 , as reported in other works [124], then the surface begins to get wet and finally stabilize.

Table 3 shows the contact angles obtained with distilled water. As can be observed, during approximately the first twenty minutes of the test the contact angle of AlcOH-Glu24 was higher than $90^{\circ}$ while in AlcOH-Glu12 the angle was greater than $90^{\circ}$ during the first minutes. The greater hydrophobicity of the $\mathrm{Al}-$ cOH-Glu24 film can be justified through the crosslinking times. The AlcOH-Glu24 film was 12 hours more in crosslinking process than the Al$\mathrm{cOH}-\mathrm{Glu} 12$, therefore, the amount of bonds formed in it is much greater, which leads to less wettability. After 30 minutes, the angles obtained are very similar.

In the case of tests with solvent ink, only the thickness of the drop in the AlcOH-Glu24 film could be measured at the initial time, obtaining a contact angle of $29.74^{\circ}$ which shows the high wettability of the inks on these films. After the first half hour, the solvent in the ink evaporated so that the height of the drops could not be recorded. In the AlcOH-Glu12 membrane, the thickness of the
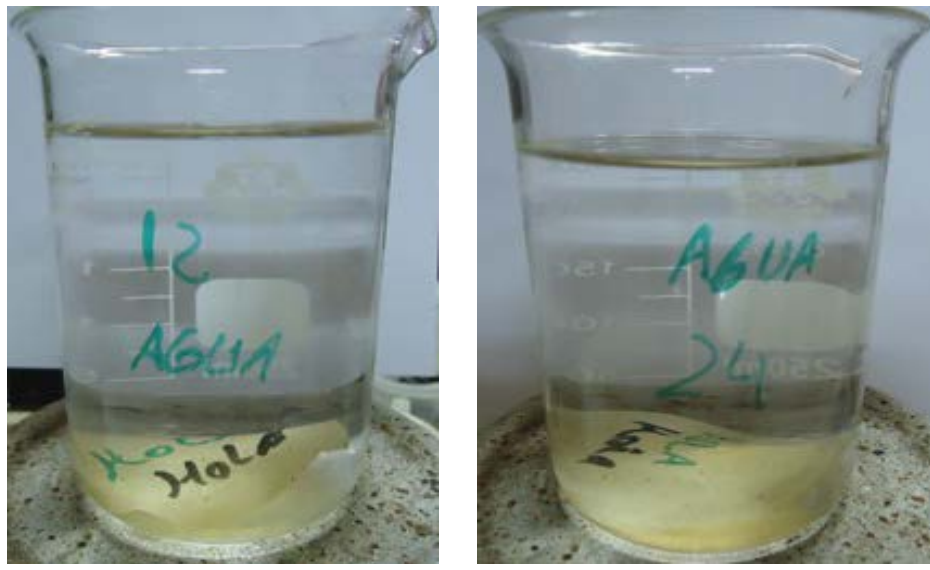

Figure 10. AlcOH-Glu24 and AlcOH-Glu12 films at the end of water absorption experiences.

Table 3. Variation of the contact angle as a function of time.

\begin{tabular}{ccc}
\hline $\mathrm{t}(\mathrm{min})$ & $\boldsymbol{\theta}_{\text {AlcOH-Glu24 }}$ & $\boldsymbol{\theta}_{\text {AlcOH-Glu12 }}$ \\
\hline 0 & $101.07^{\circ}$ & $91.33^{\circ}$ \\
15 & $92.13^{\circ}$ & $83.52^{\circ}$ \\
30 & $79.76^{\circ}$ & $77.84^{\circ}$ \\
60 & $56.68^{\circ}$ & $55.66^{\circ}$ \\
\hline
\end{tabular}


drop could not be measured since the ink wetted the film immediately and placed on it. In both films, the drop did not lose its original shape during the drying process, which would allow specific forms to be printed without the image losing definition. Figure 11 shows the ink drop at the initial time (left) and after the evaporation of the solvent (right) in the AlcOH-Glu24 film. It should be noted that these inks do not go through the film.

\subsection{Water Sorption}

This property has taken considerable interest due to its relationship with the wide range of potential applications that biopolymers have. In addition, based on the knowledge of water absorption capacity, it is possible to know the mechanical stability of the material and how it would act in contact with this solvent. The samples used in this experience were the films AlcOH-Glu2, AlcOH-Glu12 and AlcOH-Glu24.

As shown in Figure 12, the weight of the AlcOH-Glu2 film increased by
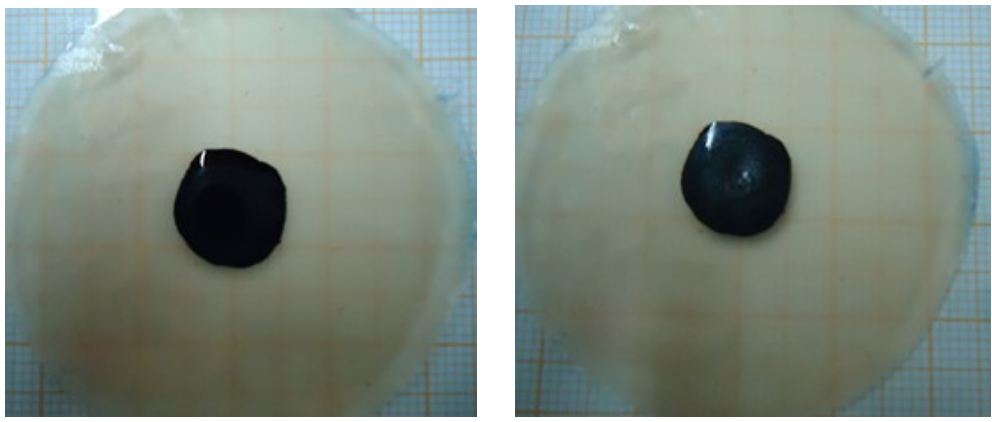

Figure 11. Measurement of the contact angle with ink in the AlcOH-GLu24 film.

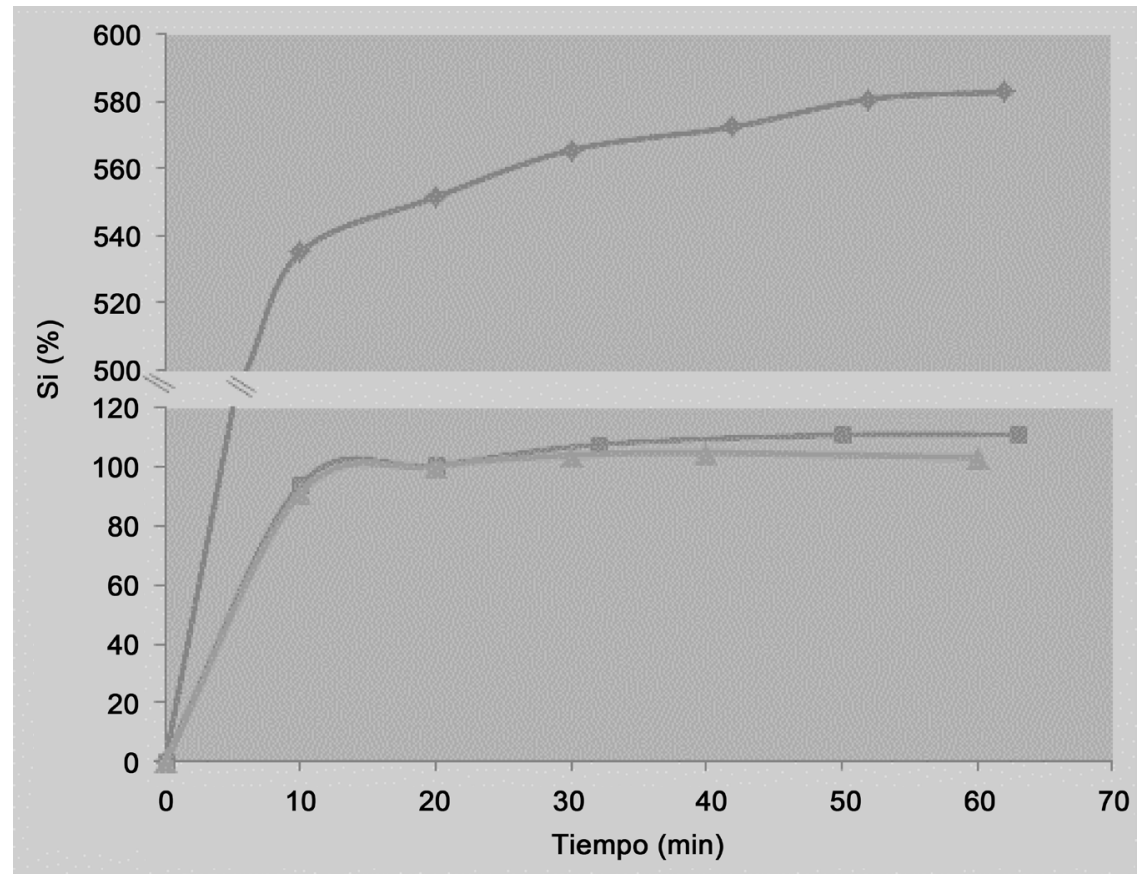

Figure 12. Swelling index $(\mathrm{Si})$ as a function of time. 
$600 \%$, while that of the AlcOH-Glu12 and AlcOH-Glu24 films increased by approximately $100 \%$. The capacity of water absorption of the membrane with two hours of crosslinking is much higher, almost $500 \%$ over that of the films AlcOH-Glu12 and AlcOH-Glu24, which acquired similar water weights. Table 4 shows the weight change suffered by some polymers when subjected to a relative humidity of $90 \%$ and a temperature of $30^{\circ} \mathrm{C}$.

As for Swelling Index (Figure 13), the change produced in the diameter of the film AlcOH-Glu2 is greater than that generated in the other films, which behaved practically the same (Figure 14).

From the tests performed on water sorption capacity, only the thickness measurement showed a difference between the films AlcOH-Glu12 and AlcOH-Glu24 (Figure 14). In the first case, the thickness reached an increase of $50 \%$ while in AlcOH-Glu24 it was $11 \%$. As in the previous tests, AlcOH-Glu2 absorbed a much higher amount of water than the other films analyzed. The large amount of water absorbed by the film AlcOH-Glu2 is related to the low degree of crosslinking it has. Data comparable for $\mathrm{AlcOH}$ with pumpkin oil cake films, see references [81] [82] [83] [84] [85]. As the crosslinking time increases,

Table 4. Swelling Index of some polymers, a [125] and b [126].

\begin{tabular}{cc}
\hline Polymer & Change of weight (\%) \\
\hline Polyacrylic acid $^{\mathrm{a}}$ & 33 \\
Polymethacrylate $^{\mathrm{a}}$ & 30 \\
Polyvinylimidazole $^{\mathrm{a}}$ & 40 \\
Polyethylene glycol $^{\mathrm{a}}$ & 73 \\
Arabinoxylane $^{\mathrm{b}}$ & $60-65$ \\
Hemicellulose $^{\mathrm{b}}$ & $45-60$ \\
\hline
\end{tabular}

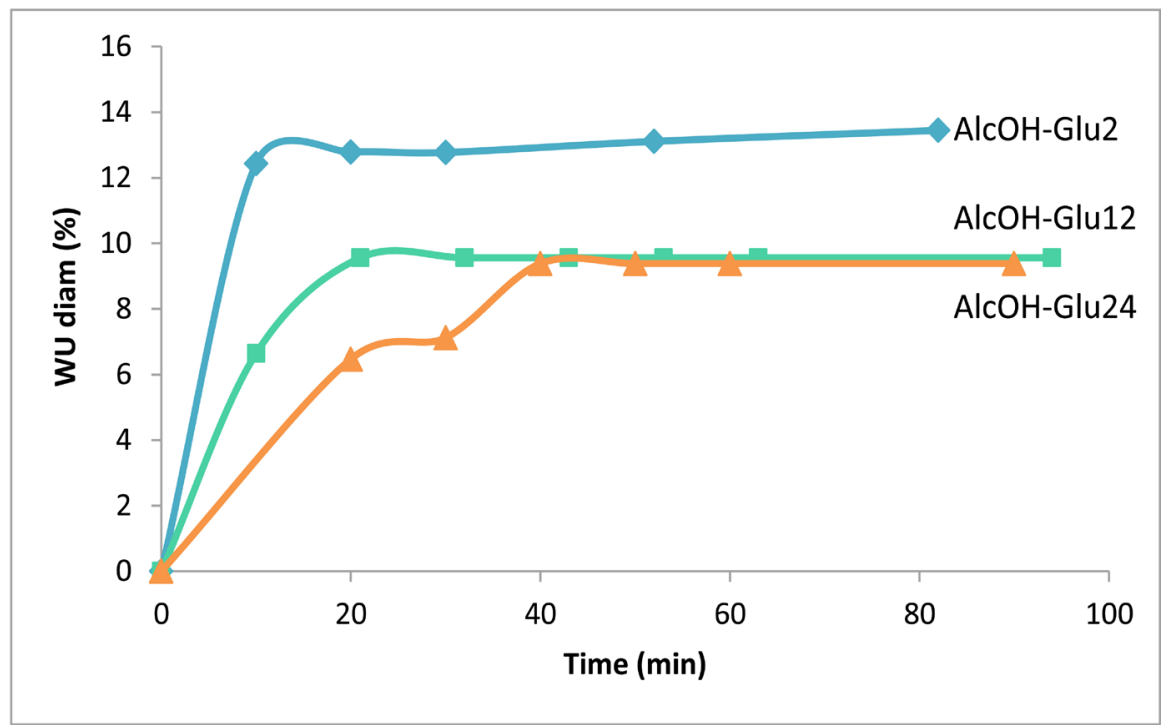

Figure 13. Measurement of water absorption (Water Up Take) through the change in diameter. 


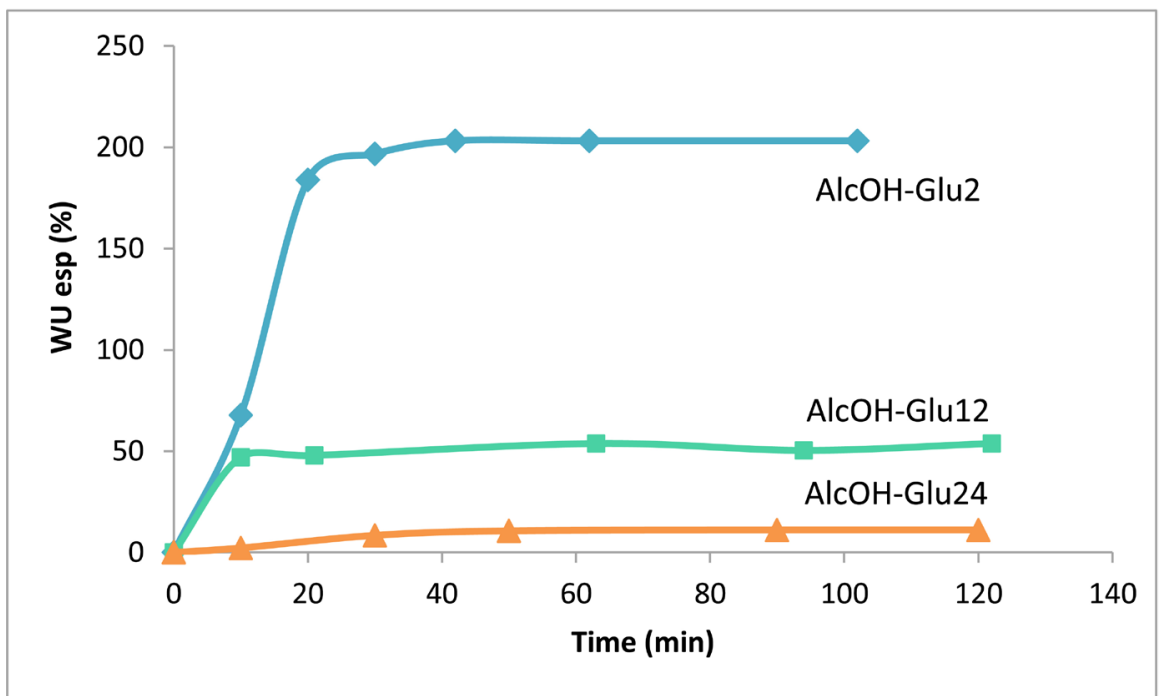

Figure 14. Measurement of water absorption (Water Up Take) through the change in thickness.

the amount of bonds formed prevents the absorption of large amounts of water. The minimum absorption capacity is presented by the film AlcOH-Glu24, however, the difference with the film AlcOH-Glu12 is very small, and it can be concluded that the increase in the number of links, after 12 hours of crosslinking, practically no modifies the absorption capacity of the films.

\subsection{Barrier Properties}

One of the most important properties that characterize the materials are the barrier properties, both water vapor permeability and gas permeation will determine the possible applications of the material under study.

Water Vapor Permeability. The knowledge of the water vapor permeability allows to know the capacity of the material as a barrier to the passage of water and as a function of this, to evaluate what type of food can be packed. For some foods, the greater the barrier, the more suitable the material becomes, as it prevents the food from becoming dehydrated, as well as protecting the packaged food from environmental humidity. On the contrary, other foods need very permeable packages, thus reducing the activity of the water inside the container and preventing the growth of microorganisms.

The water vapor permeability was measured in a hermetically sealed chamber at $30^{\circ} \mathrm{C}$ and $90 \%$ relative humidity. The permeability values obtained for the membranes AlcOH-Glu24, AlcOH-Glu12 and $\mathrm{AlcOH}$ (an uncrosslinked film) are shown in Table 5. Data comparable for AlcOH with pumpkin oil cake films, see references [81-85].

As would be expected, non-crosslinked film (AlcOH) is more permeable than crosslinked films. Permeability was obtained around three times higher than in the crosslinked films, which presented similar values, although AlcOH-Glu24 had the lowest permeability due to the longer crosslinking time. 
Table 5. Water vapor permeability of the films obtained.

\begin{tabular}{cc}
\hline Films & $\mathrm{P}\left(\mathrm{ng} \mathrm{m} / \mathrm{m}^{2} \mathrm{sa}\right)$ \\
\hline AlcOH & 0.608 \\
AlcOH-Glu12 & 0.232 \\
AlcOH-Glu24 & 0.159 \\
\hline
\end{tabular}

Table 6. Water vapor permeability of some polymers [126] [127].

\begin{tabular}{cc}
\hline Films & $\mathrm{P}\left(\mathrm{ng} \mathrm{m} / \mathrm{m}^{2} \mathrm{~s} \mathrm{~Pa}\right)$ \\
PEHD & 0.00024 \\
PELD & $0.00073-0.00097$ \\
Polyester & $0.0012-0.0015$ \\
Cellophane & $0.077-0.084$ \\
Cellulose acetate & $0.005-0.016$ \\
High amylose starch & $0.2-1$ \\
Wheat gluten & $1.4-4.6$ \\
Soy protein isolate & $1.6-4.4$ \\
Gelatin & $2.83-5.66$ \\
\hline
\end{tabular}

Although the addition of glycerin generates an increase in permeability, the formation of bonds during crosslinking counteracts and reverses this result, obtaining films with lower water vapor permeabilities.

By way of comparison, the water vapor permeability values of other polymers, both synthetic and biodegradable, are shown in Table 6 .

The values obtained are much higher than the permeability coefficients of synthetic polymers and lower than those of biopolymer films such as gelatin, soy protein and gluten. The films obtained with alcayota polysaccharides showed a water vapor permeability similar to that presented by the starch films [128].

Gas Permeation: Because the AlcOH film does not contain glycerin, its permeability to different gases is lower. Furthermore, since it has been hydrolyzed, it has a large number of hydroxyl groups that generate interactions between the chains, mainly hydrogen bridges, which contributes to obtaining lower permeabilities [129]. In the film AlcOH-Glu12 the following order was obtained in the permeability coefficients: $\mathrm{P}_{\mathrm{CO} 2}>\mathrm{P}_{\mathrm{O} 2}>\mathrm{P}_{\mathrm{N} 2}$. In polymer films, more than the size of the molecule, they matter the chemical nature and structure of the polymer that makes up the material as well as their interactions with the gases. The transport of gas molecules through the polymer matrix occurs through the mechanisms of sorption and diffusion, so differences in the permeabilities of different gases can occur due to differences in their solubilities and/or diffusivities [87]. Data comparable for $\mathrm{AlcOH}$ with pumpkin oil cake films, see references [81] [82] [83] [84] [85]. The coefficients of permeability of nitrogen, oxygen and carbon dioxide, as well as the permeoselectivities were calculated. The results obtained are shown in Table 7. 
The greater permeability of the film AlcOH-Glu12 with respect to AlcOH can be explained through the free volume. During the intercrossing, molecules enter the film that generates the separation of the polymer chains, consequently, the free volume increases with the consequent increase in permeability [130]. As the time of crosslinking increases, the number of bonds formed increases progressively, reducing these spaces and decreasing permeability [129]. This could not be proven since the film AlcOH-Glu24 was broken when placed in the permeation cell due to the rigidity it acquired as a result of the extremely long crosslinking process.

\subsection{Mechanical Properties}

In order to know the behavior of the films against the application of a tensile stress and the effect of crosslinking in them, mechanical tests of the films Al$\mathrm{cOH}, \mathrm{AlcOH}-\mathrm{Glu} 12$ and AlcOH-Glu24 were made, and results are shown in Figure 15. Table 8 summarizes the most important mechanical properties of the films studied.

As can be seen, the AlcOH film showed very low values of tensile strength and Young's modulus, while the elongation obtained was intermediate. This film did

Table 7. Permeability coefficients and permeoselectivities of the films studied.

\begin{tabular}{ccc}
\hline Film & AlcOH & AlcOH-Glu12 \\
\hline Thickness $(\mu \mathrm{m})$ & 93.13 & 27.85 \\
$\mathrm{P}_{\mathrm{N} 2}$ (Barrer) & 0.130 & 0.214 \\
$\mathrm{P}_{\mathrm{O} 2}$ (Barrer) & 0.039 & 0.228 \\
$\mathrm{P}_{\mathrm{CO} 2}$ (Barrer) & 0.029 & 0.376 \\
$\alpha_{\mathrm{O} 2 / \mathrm{N} 2}$ & 0.303 & 1.065 \\
$\alpha_{\mathrm{O} 2 / \mathrm{CO} 2}$ & 1.353 & 0.606 \\
$\alpha_{\mathrm{CO} 2 / \mathrm{O} 2}$ & 0.739 & 1.649 \\
\hline
\end{tabular}

Barrer $=10^{-10} \mathrm{~cm}^{3}(\mathrm{STP}) \mathrm{cm} / \mathrm{cm}^{2} \mathrm{~s} \mathrm{cmHg}$.

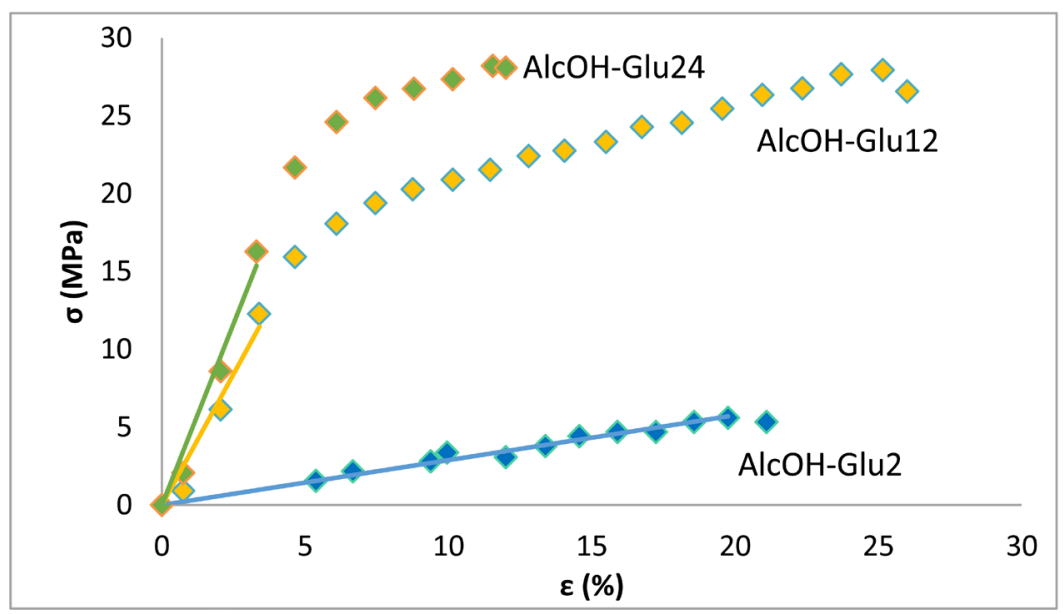

Figure 15. Curves $(\sigma)$ versus $(\varepsilon)$. 
Table 8. Resistance to tension, maximum elongation and young's modulus.

\begin{tabular}{cccc}
\hline Films & $\sigma(\mathrm{MPa})$ & $\mathcal{E}(\%)$ & Young's Modulus (MPa) \\
\hline AlcOH & 5.59 & 21 & 28.5 \\
AlcOH-Glu12 & 27.93 & 25 & 336.86 \\
AlcOH-Glu24 & 28.2 & 13 & 465.41 \\
\hline
\end{tabular}

not suffer any kind of chemical modification, so it is a film with few intermolecular associations.

The other films analyzed were hydrolyzed and crosslinked, so that resistance and Young's modules were obtained, which are much higher and similar to each other, although one of the films has twelve more hours of crosslinking.

The film AlcOH-Glu12 is the one with the highest elongation. This is the result of the action of glycerol. As mentioned above, the incorporation of the molecules of the plasticizing agent in the films establishes hydrogen bonds between the glycerin molecule and the polysaccharide molecule, replacing some polysaccharide-polysaccharide interactions. As a result, direct interactions between polymer molecules are reduced and mobility is increased, causing an increase in elongation [131]. Probably also a lubricating effect and an increase in free volume will occur, facilitating the movement of the molecules. While the amount of plasticizer added to the AlcOH-Glu24 film was the same as that of Al$\mathrm{cOH}-\mathrm{Glu} 12$, the former exhibited a much lower elongation, even less than that of the uncrosslinked film. This is due to the excessive intercrossing time to which the film was subjected. During the 24 hours of crosslinking a large amount of bonds was formed, adding to this the high number of hydroxyl groups (formed during hydrolysis) that generate hydrogen bonds, a polymeric network with a large number of interactions between the chains is obtained which immobilizes the molecules. Consequently, high tensile strength and very low elongation are obtained [96] [116] [131]-[138]. Data comparable for AlcOH with pumpkin oil cake films, see references [81] [82] [83] [84] [85].

\subsection{Colorimetry}

The color of the materials, as well as the design and colors used in the packaging already printed, are part of the marketing of the product and can determine the acceptability or not of a product in the market. The opacity and color of the Al$\mathrm{cOH}$, AlcOH-Glu12, AlcOH-Glu24 and AlcOH-Glu24' films were determined and its results are shown in Table 9.

The AlcOH, AlcOH-12hs and $\mathrm{AlcOH}-24 \mathrm{hs}$ films presented approximately the same light caramel color. Figure 16 shows the area corresponding to the color of the films, and shows the film in which the darkest color was obtained (Figure 17).

The film AlcOH-Glu24' is a film obtained in the same way as the AlcOH-Glu24 but which was also subjected to an ethanoic wash prior to crosslinking in order to obtain a clearer film, since ethanol extracts the components that give it color (Figure 18). 
Table 9. Opacity and colour parameters.

\begin{tabular}{ccccc}
\hline Films & $\mathrm{L}^{*}$ & $\mathrm{a}^{*}$ & $\mathrm{~b}^{*}$ & OP \\
\hline AlcOH & 72.68 & 8.49 & 27.77 & 99.97 \\
AlcOH-Glu12 & 74.71 & 6.32 & 30.30 & 99.93 \\
AlcOH-Glu24 & 54.30 & 18.14 & 41.27 & 101.87 \\
AlcOH-Glu24' & 82.16 & 2.63 & 16.66 & 94.41 \\
\hline
\end{tabular}

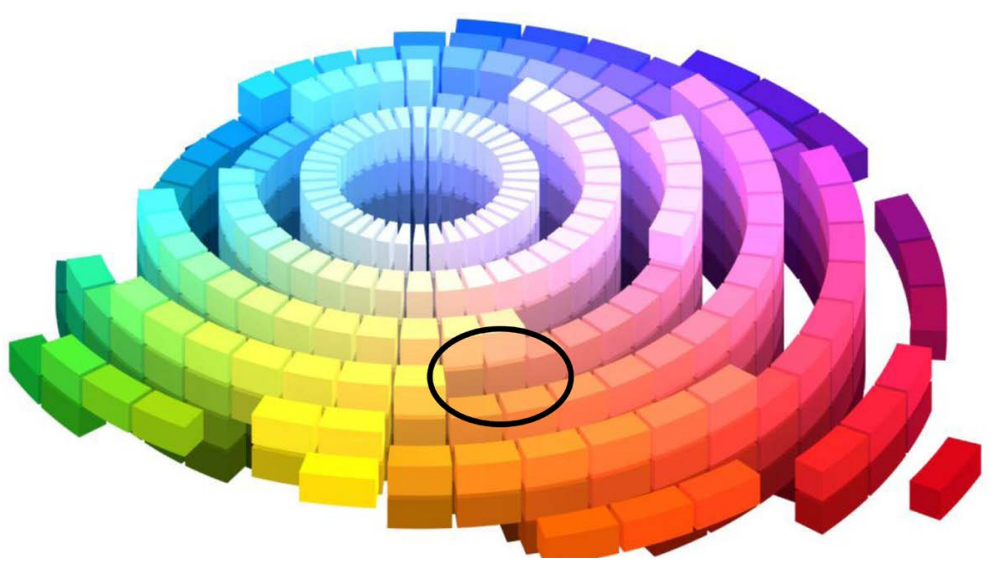

Figure 16. Zone that represents the color of the films in the CIELAB space.

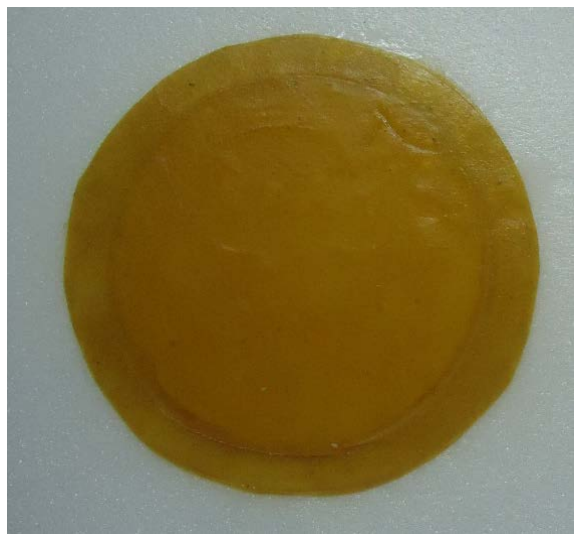

Figure 17. Colour of AlcOH-Glu24 film.

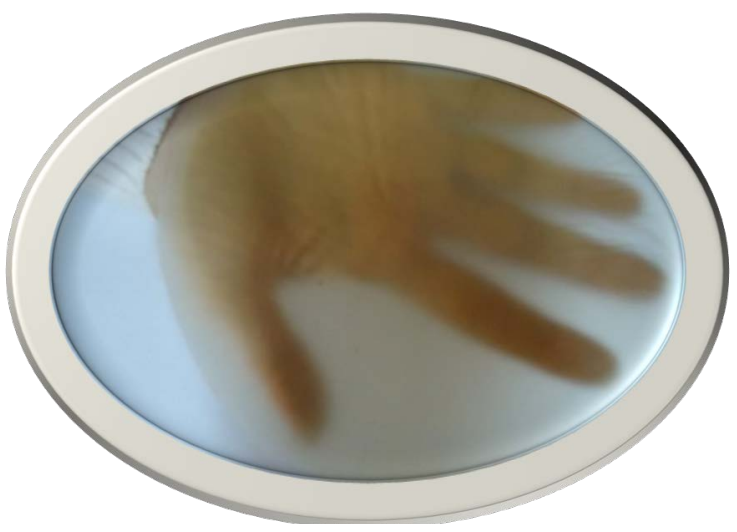

Figure 18. Film AlcOH-Glu24'. 
It is observed that the obtained film is very clear and much more transparent than those which did not undergo this ethanoic treatment prior to crosslinking.

\subsection{Biodegradability}

In order to know the time needed to degrade the films obtained, biodegradability tests were carried out. The samples were placed at a depth of $2 \mathrm{~cm}$ in a soil sample with $83 \%$ humidity and placed in an oven at $30^{\circ} \mathrm{C}$. These extreme conditions were selected to accelerate the rate of degradation and thus be able to obtain results in a reasonable period in order to be presented in this work. The data selected to make the graphs were the measurements of the transversal length of the samples as time progressed. The weight could not be used due to the high capacity of water absorption, which led to the fact that even in the last measurement made (at 32 days in the film AlcOH-Glu24) the weight measured was higher than the original, not being able to get the weight decrease due to its degradation.

Figure 19 shows the data obtained expressed as a percentage change in length as time progresses. It is observed that the non-crosslinked film was degraded in 12 days, while the crosslinked films took several more days. In the case of Al$\mathrm{cOH}-\mathrm{Glu} 12$, the degradation time was 25 days and in AlcOH-Glu24, 32 days.

The degradation speed of the films is presented in Table 10. It is observed that the degradation rate of the crosslinked film AlcOH-Glu12 is approximately half that of the non-crosslinked film. The rate of degradation decreases as the degree of crosslinking increases until it reaches, in the AlcOH-Glu24 film, almost one third of the speed of the non-crosslinked film

\subsection{Sensory Tests of Packaged Foods}

In the validation stage of the design, it is essential to test the fabricated part in its final form to ensure that the requirements have been met. Such tests have specific applications and frequently involve tests in real or simulated service conditions that employ methods or procedures, in general, not standardized [102].

Sensory tests (color, aroma, taste and appearance) of the packaged foods were made with the films: AlcOH, AlcOH-Glu12 and AlcOH-Glu24. The test was carried out for five weeks, analyzing the samples every seven days.

The commercial common sugar showed no sensory changes during the experience in any of the tested containers.

Table 11 shows the results obtained for the milk powder samples. The letter $\mathrm{N}$ was used to denote normality in the property, that is, when no difference was detected compared with the sample preserved in its original container. The + symbol indicates a slight perception of worsening in the analyzed parameter, while the double symbol ++ means that the deterioration detected is higher than the simple symbol $(+)$.

As shown in Table 11, in the case of milk powder, no sensory changes occurred during the first 21 days. In the fourth week, the packaged sample with the 


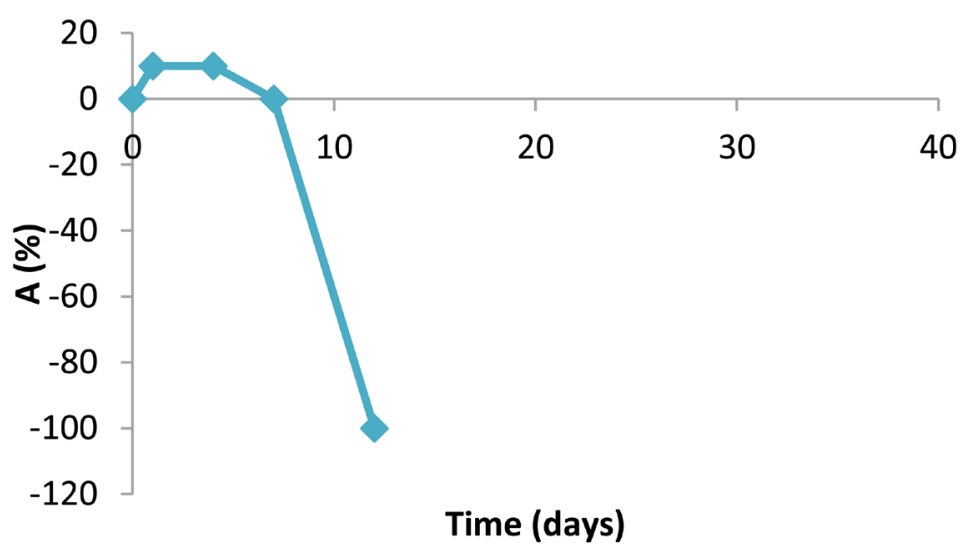

(a)

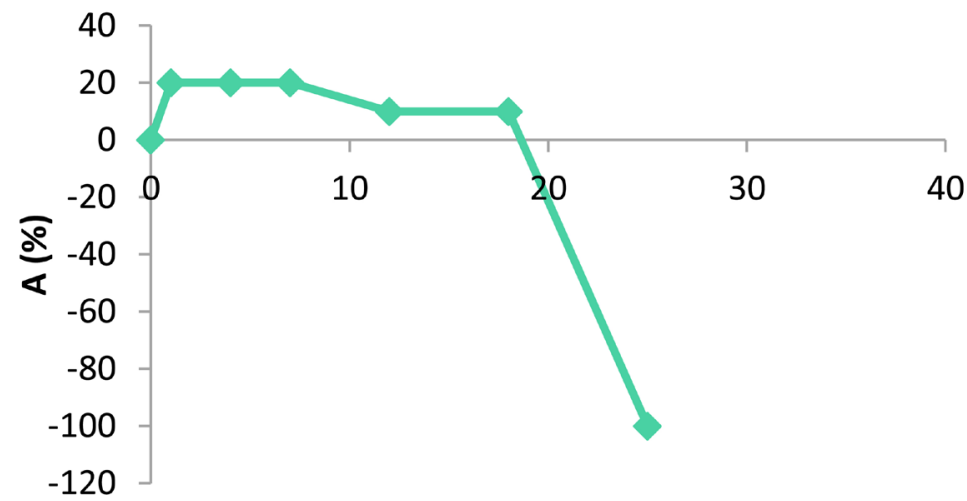

Time (days)

(b)

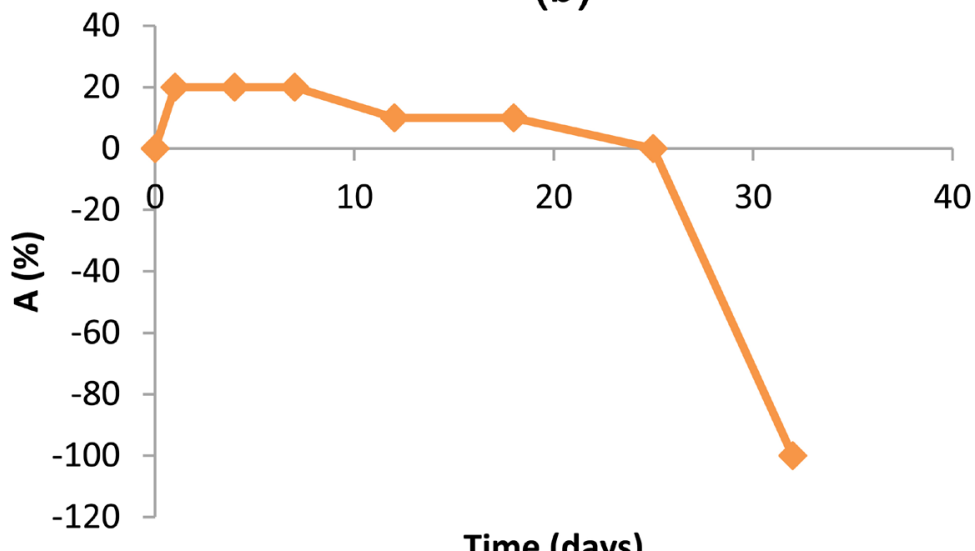

(c)

Figure 19. Biodegradability of films: (a) AlcOH, (b) AlcOH-Glu12, (c) AlcOH-Glu24.

Table 10. Degradation speed of the films.

\begin{tabular}{cc}
\hline Films & Degradation speed (mm/day) \\
\hline AlcOH & 0.83 \\
AlcOH-Glu12 & 0.40 \\
AlcOH-Glu24 & 0.31 \\
\hline
\end{tabular}


Table 11. Results of sensory tests on whole milk powder.

\begin{tabular}{|c|c|c|c|c|}
\hline Films & Colour & Aroma & Taste & Aspect \\
\hline & & Week 1 & & \\
\hline $\mathrm{AlcOH}$ & $\mathrm{N}$ & $\mathrm{N}$ & $\mathrm{N}$ & $\mathrm{N}$ \\
\hline AlcOH-Glu12 & $\mathrm{N}$ & $\mathrm{N}$ & $\mathrm{N}$ & $\mathrm{N}$ \\
\hline \multirow[t]{2}{*}{ AlcOH-Glu124 } & $\mathrm{N}$ & $\mathrm{N}$ & $\mathrm{N}$ & $\mathrm{N}$ \\
\hline & & Week 2 & & \\
\hline $\mathrm{AlcOH}$ & $\mathrm{N}$ & $\mathrm{N}$ & $\mathrm{N}$ & $\mathrm{N}$ \\
\hline AlcOH-Glu12 & $\mathrm{N}$ & $\mathrm{N}$ & $\mathrm{N}$ & $\mathrm{N}$ \\
\hline \multirow[t]{2}{*}{ AlcOH-Glu124 } & $\mathrm{N}$ & $\mathrm{N}$ & $\mathrm{N}$ & $\mathrm{N}$ \\
\hline & & Week 3 & & \\
\hline $\mathrm{AlcOH}$ & $\mathrm{N}$ & $\mathrm{N}$ & $\mathrm{N}$ & $\mathrm{N}$ \\
\hline AlcOH-Glu12 & $\mathrm{N}$ & $\mathrm{N}$ & $\mathrm{N}$ & $\mathrm{N}$ \\
\hline \multirow[t]{2}{*}{ AlcOH-Glu124 } & $\mathrm{N}$ & $\mathrm{N}$ & $\mathrm{N}$ & $\mathrm{N}$ \\
\hline & & Week 4 & & \\
\hline $\mathrm{AlcOH}$ & $\mathrm{N}$ & $\mathrm{N}$ & + & $\mathrm{N}$ \\
\hline AlcOH-Glu12 & $\mathrm{N}$ & $\mathrm{N}$ & $\mathrm{N}$ & $\mathrm{N}$ \\
\hline \multirow[t]{2}{*}{ AlcOH-Glu124 } & $\mathrm{N}$ & $\mathrm{N}$ & $\mathrm{N}$ & $\mathrm{N}$ \\
\hline & & Week 5 & & \\
\hline $\mathrm{AlcOH}$ & $\mathrm{N}$ & $\mathrm{N}$ & ++ & $\mathrm{N}$ \\
\hline AlcOH-Glu12 & $\mathrm{N}$ & $\mathrm{N}$ & + & $\mathrm{N}$ \\
\hline AlcOH-Glu124 & $\mathrm{N}$ & $\mathrm{N}$ & $\mathrm{N}$ & $\mathrm{N}$ \\
\hline
\end{tabular}

film AlcOH showed a slight rancidity, noticeable in the taste, but not in the aroma, which increased in the fifth week, possibly this is due to increased permeability of water vapor respect to other movies. In the last week the sample packed in AlcOH-Glu12 presented a slight rancidity very little noticeable. It should be considered that the samples were kept at $30^{\circ} \mathrm{C}$, a relatively high temperature that favors the oxidation process of fats.

This test was useful to know the behavior of the foods to be packed with the films obtained. The commercial containers of whole milk powder that use a metallic bag inside a cardboard box, ensure to keep the good properties of the product for 30 days once the container has been opened. In our case, rancidity was detected in the fifth week of testing, it can be said then that conservation times are comparable. The comparison is made between open containers because, to perform the analysis, we had to open the container once a week. Even if these results were obtained, if the tests were carried out in closed containers, shorter storage times would be obtained with respect to the commercial package due to the higher permeability of the films obtained. This is a problem to solve in most biomaterials so many current research aims to improve the permeability of this type of materials to extend its field of application. 


\section{Conclusions}

A series of preliminary operations were carried out on the fruit in order to obtain a flour from which the films were made. These operations included the peeling and the separation of the seeds, then the pulp was chopped and a dehydration process was carried out until obtaining a 3\% humidity. Finally, the grinding was carried out.

From this flour, a purification process was proposed, consisting of the solid-liquid extraction of undesirable compounds, followed by a purification by ethanoic precipitation. Then, a basic hydrolysis is carried out, whose objective is to generate hydroxyl groups and obtain polysaccharides of lower molecular weight and water soluble [139]. The plasticizing agent is added and molded. After evaporation of the solvent, water soluble films are obtained and very low mechanical stability. To solve this problem, it was used glutaraldehyde as a crosslinking agent [140].

Through the SEM images obtained it was possible to know the surface morphology of the films, it was found that the crosslinking process modifies this morphology obtaining much more irregular surfaces. The shape and size of the dispersed particles in the matrix were also observed, which correspond to aggregates of macromolecules of larger size. In addition, the absence of bacterial contamination was verified through elemental analysis, observing in addition an increase in the amount of carbon and oxygen and a decrease in alkaline and alkaline earth metals due to the crosslinking process.

The films obtained are totally insoluble in water, mechanically resistant when they are submerged in this solvent and are not affected when the temperature increases. Its resistance was also proved by being submerged in acidic and basic aqueous solutions.

The resistance of the inks tested when immersing the films in water allowed us to conclude that it is possible to print on them. The same result was obtained by the contact angle, in this test it was observed that the film presents a high wettability by the inks, but not by the water, with which angles greater than $90^{\circ}$ were obtained, which demonstrates its hydrophobicity.

Although the films are insoluble in water, they have a high absorption capacity. The films with 12 and 24 hours of crosslinking presented practically the same absorption, while that with only two hours of crosslinking presented an absorption almost 500\% higher in weight than those with a higher degree of crosslinking.

The films became less permeable to water vapor as the degree of crosslinking increased, which is in accordance with the results of the contact angle test, in which the hydrophobicity of said films was demonstrated. However, the water vapor permeabilities obtained are much higher compared to synthetic polymer films, although similar to the permeability coefficients of films of other biopolymers. In particular, they presented values very similar to those found in starch films. 
In terms of gas permeation, the AlcOH-Glu12 film was more permeable to carbon dioxide than to oxygen, a conclusion that determines what foods can be packed in these materials, with dehydrated foods containing fats being a possibility.

The two crosslinked films that were analyzed (AlcOH-Glu12 and AlcOH-Glu24) showed similar resistances to Young's modulus and tension, but their elongations presented a great difference: while the film with 24 hours of crosslinking had only $13 \%$ elongation, the other exceeded $25 \%$.

With the proposed synthesis process, caramel colored films of greater or lesser intensity are obtained. However, a clear and more transparent film was obtained through a series of ethanolic washes prior to the crosslinking process.

Fully biodegradable films were obtained with very high degradation rates due to the test conditions $\left(\mathrm{T}=30^{\circ} \mathrm{C}\right.$ and $\left.\mathrm{RH}=83 \%\right)$. The crosslinked films Al$\mathrm{cOH}-\mathrm{Glu} 12$ and AlcOH-Glu24 took 25 and 32 days respectively to completely degrade. Under normal conditions of soil temperature and humidity, the time required for biodegradation would be much longer than that obtained.

The sensory tests performed were very useful to know the behavior of the films under real conditions of use. In general, the result was positive. Packaged sugar was obtained without noticeable changes in any of its organoleptic properties after five weeks of analysis. In the case of whole milk powder packed in the film with 12 hours of crosslinking, it became rancid after one month of packaging, a result comparable to the commercial packages currently used.

Comparing the properties of alcayota films with those of other biopolymers, it is concluded that the films obtained are less permeable than those of soy and gelatin and that they have a permeability similar pumpkin oil cake (PuOC compared only with $\mathrm{AlcOH}$ film), pectin, starch and guar gum. As for the tensile strength, they presented intermediate values, surpassed only by guar gum films. The film AlcOH-Glu12 stands out in terms of its elongation, which was higher than the rest of the films, with the exception of soy films. The Young's modulus obtained in the alcayota films was inferior to that of the pectin and starch films, demonstrating its greater flexibility.

As a general conclusion, it can be said that the best film obtained is the AlcOH-Glu12, since compared to the AlcOH-Glu24 film it had a similar water absorption capacity, it is equally insoluble, it has better mechanical properties, the vapor permeability coefficient of water obtained is similar and also presents 12 hours less crosslinking. The only advantage that the film would exhibit with 24 hours of crosslinking is the lower gas permeation, which could not be measured by its poor mechanical properties.

\section{Acknowledgements}

The authors thank Universidad Nacional de San Luis and Instituto de Física Aplicada (INFAP-CONICET). The UNSL projects 2-1712, 2-2414 and 2-1916 for their financial support. 


\section{References}

[1] Cazón, P., Velazquez, G., Ramírez, J.A. and Vázquez, M. (2017) Polysaccharide-Based Films and Coatings for Food Packaging: A Review. Food Hydrocolloids, 68, 136-148. https://doi.org/10.1016/j.foodhyd.2016.09.009

[2] Dhall, R.K. (2015) Application of Edible Coatings on Fruits and Vegetables. In: Tiwari, A., Galanis, A. and Soucek, M.D., Eds., Biobased and Environmental Benign Coatings, Scrivener Publishing, Wiley, Chapter 4.

[3] Poyatos-Racionero, E., Ros-Lis, J.V., Vivancos, J.L. and Martínez-Máñez, R. (2018) Recent Advances on Intelligent Packaging as Tools to Reduce Food Waste. Journal of Cleaner Production, 172, 3398-3409. https://doi.org/10.1016/j.jclepro.2017.11.075

[4] Silva-Weiss, A., Ihl, M., Sobral, P.J.A., Gómez-Guillén, M.C. and Bifani, V. (2013) Natural Additives in Bioactive Edible Films and Coatings: Functionality and Applications in Foods. Food Engineering Reviews, 5, 200-216. https://doi.org/10.1007/s12393-013-9072-5

[5] Bonilla, J., Atarés, L., Vargas, M. and Chiralt, A. (2012) Edible Films and Coatings to Prevent the Detrimental Effect of Oxygen on Food Quality: Possibilities and Limitations. Journal of Food Engineering, 110, 208-213.

https://doi.org/10.1016/j.jfoodeng.2011.05.034

[6] Dehghani, S., Hosseini, S.V. and Regenstein, J.M. (2018) Edible Films and Coatings in Seafood Preservation: A Review. Food Chemistry, 240, 505-513.

https://doi.org/10.1016/j.foodchem.2017.07.034

[7] Wang, P.C., Zhao, S., Yang, B.Y., Wang, Q.H. and Kuang, H.X. (2016) Anti-Diabetic Polysaccharides from Natural Sources: A Review. Carbohydrate Polymers, 148, 86-97. https://doi.org/10.1016/j.carbpol.2016.02.060

[8] De Dicastillo, C.L., Rodríguez, F., Guarda, A. and Galotto, M. J. (2016) Antioxidant Films Based on Cross-Linked Methyl Cellulose and Native Chilean Berry for Food Packaging Applications. Carbohydrate Polymers, 136, 1052-1060. https://doi.org/10.1016/j.carbpol.2015.10.013

[9] Razzaq, H.A., Pezzuto, M., Santagata, G., Silvestre, C., Cimmino, S., Larsen, N. and Duraccio, D. (2016) Barley $\beta$-Glucan-Protein Based Bioplastic Film with Enhanced Physicochemical Properties for Packaging. Food Hydrocolloids, 58, 276-283. https://doi.org/10.1016/j.foodhyd.2016.03.003

[10] Jaramillo, C.M., Gutiérrez, T.J., Goyanes, S., Bernal, C. and Famá, L. (2016) Biodegradability and Plasticizing Effect of Yerba Mate Extract on Cassava Starch Edible Films. Carbohydrate Polymers, 151, 150-159. https://doi.org/10.1016/j.carbpol.2016.05.025

[11] Romero, V., Borneo, R., Passalacqua, N. and Aguirre, A. (2016) Biodegradable Films Obtained from Triticale (x Triticosecale Wittmack) Flour Activated with Natamycin for Cheese Packaging. Food Packaging and Shelf Life, 10, 54-59. https://doi.org/10.1016/j.fpsl.2016.09.003

[12] Simkovica, I., Mendichi, R., Kelnar, I., Filipa, J. And Hricovíni, M. (2015) Cationization of Heparin for Film Applications. Carbohydrate Polymers, 115, 551-558. https://doi.org/10.1016/j.carbpol.2014.09.021

[13] Encalada, A.M.I., Basanta, M. F., Fissore, E.N., De’Nobili, M.D. and Rojas, A.M. (2016) Carrot fiber (CF) Composite Films for Antioxidant Preservation: Particle Size Effect. Carbohydrate Polymers, 136, 1041-1051.

https://doi.org/10.1016/j.carbpol.2015.09.109 
[14] Zhang, P., Zhao, Y. and Shi, Q. (2016) Characterization of a Novel Edible Film Based on Gum Ghatti: Effect of Plasticizer Type and Concentration. Carbohydrate Polymers, 153, 345-355. https://doi.org/10.1016/j.carbpol.2016.07.082

[15] Garrido, T., Etxabide, A., Guerrero, P. and De la Caba, K. (2016) Characterization of Agar/Soy Protein Biocomposite Films: Effect of Agar on the Extruded Pellets and Compression Moulded Films. Carbohydrate Polymers, 151, 408-416. https://doi.org/10.1016/j.carbpol.2016.05.089

[16] Farhan, A. and Hani, N.M. (2017) Characterization of Edible Packaging Films Based on Semi-Refined Kappa-Carrageenan Plasticized with Glycerol and Sorbitol. Food Hydrocolloids, 64, 48-58. https://doi.org/10.1016/j.foodhyd.2016.10.034

[17] Aranaz, I., Harris, R., Navarro-García, F., Heras, A. and Acosta, N. (2016) Chitosan Based Films as Supports for Dual Antimicrobial Release. Carbohydrate Polymers, 146, 402-410. https://doi.org/10.1016/j.carbpol.2016.03.064

[18] Vargas, C.G., Costa, T.M.H., de Oliveira Rios, A. And Flôres, S.H. (2017) Comparative Study on the Properties of Films Based on Red Rice (Oryza glaberrima) Flour and Starch. Food Hydrocolloids, 65, 96-106.

https://doi.org/10.1016/j.foodhyd.2016.11.006

[19] Liu, S., Li, Y. and Li, L. (2017) Enhanced Stability and Mechanical Strength of Sodium Alginate Composite Films. Carbohydrate Polymers, 160, 62-70. https://doi.org/10.1016/j.carbpol.2016.12.048

[20] Zhang, N., Xu, J., Gao, X., Fu, X. and Zheng, D. (2017) Factors Affecting Water Resistance of Alginate/Gellan Blend Films on Paper Cups for Hot Drinks. Carbohydrate Polymers, 156, 435-442. https://doi.org/10.1016/j.carbpol.2016.08.101

[21] Espitia, P.J.P., Du, W.X., de Jesús Avena-Bustillos, R., Soares, N.D.F.F. and McHugh, T.H. (2014) Edible Films from Pectin: Physical-Mechanical and Antimicrobial Properties-A Review. Food Hydrocolloids, 35, 287-296. https://doi.org/10.1016/j.foodhyd.2013.06.005

[22] Mostafavi, F.S., Kadkhodaee, R., Emadzadeh, B. and Koocheki, A. (2016) Preparation and Characterization of Tragacanth-Locust Bean Gum Edible Blend Films. Carbohydrate Polymers, 139, 20-27. https://doi.org/10.1016/j.carbpol.2015.11.069

[23] Bilanovic, D., Starosvetsky, J. and Armon, R.H. (2016) Preparation of Biodegradable Xanthan-Glycerol Hydrogel, Foam, Film, Aerogel and Xerogel at Room Temperature. Carbohydrate Polymers, 148, 243-250. https://doi.org/10.1016/j.carbpol.2016.04.058

[24] Ma, Q., Du, L., Yang, Y. and Wang, L. (2017) Rheology of Film-Forming Solutions and Physical Properties of Tara Gum Film Reinforced with Polyvinyl Alcohol (PVA). Food Hydrocolloids, 63, 677-684. https://doi.org/10.1016/j.foodhyd.2016.10.009

[25] Sousa, A.M. and Gonçalves, M.P. (2015) Strategies to Improve the Mechanical Strength and Water Resistance of Agar Films for Food Packaging Applications. Carbohydrate Polymers, 132, 196-204. https://doi.org/10.1016/j.carbpol.2015.06.022

[26] Gřundělová, L., Gregorová, A., Mráček, A., Vícha, R., Smolka, P. and Minařík, A. (2015) Viscoelastic and Mechanical Properties of Hyaluronan Films and Hydrogels Modified by Carbodiimide. Carbohydrate Polymers, 119, 142-148. https://doi.org/10.1016/j.carbpol.2014.11.049

[27] Foglarová, M., Chmelař, J., Huerta-Angeles, G., Vágnerová, H., Kulhánek, J., Tománková, K.B., Velebný, V., et al. (2016) Water-Insoluble Thin Films from Palmitoyl Hyaluronan with Tunable Properties. Carbohydrate Polymers, 144, 68-75. https://doi.org/10.1016/j.carbpol.2016.02.027 
[28] Marvdashti, L.M., Koocheki, A. and Yavarmanesh, M. (2017) Alyssum Homolocarpum Seed Gum-Polyvinyl Alcohol Biodegradable Composite Film: Physicochemical, Mechanical, Thermal and Barrier Properties. Carbohydrate Polymers, 155, 280-293. https://doi.org/10.1016/j.carbpol.2016.07.123

[29] Du, H., Hu, Q., Yang, W., Pei, F., Kimatu, B.M., Ma, N., Zhao, L., et al. (2016) Development, Physiochemical Characterization and Forming Mechanism of Flammulina velutipes Polysaccharide-Based Edible Films. Carbohydrate Polymers, 152, 214-221. https://doi.org/10.1016/j.carbpol.2016.07.035

[30] Dick, M., Costa, T.M.H., Gomaa, A., Subirade, M., de Oliveira Rios, A. and Flôres, S.H. (2015) Edible Film Production from Chia Seed Mucilage: Effect of Glycerol Concentration on Its Physicochemical and Mechanical Properties. Carbohydrate Polymers, 130, 198-205. https://doi.org/10.1016/j.carbpol.2015.05.040

[31] Qi, G., Li, N., Sun, X.S., Shi, Y.C. and Wang, D. (2016) Effects of Glycerol and Nanoclay on Physiochemical Properties of Camelina Gum-Based Films. Carbohydrate Polymers, 152, 747-754. https://doi.org/10.1016/j.carbpol.2016.07.068

[32] Yang, H., Wen, X.L., Guo, S.G., Chen, M.T., Jiang, A.M. and Lai, L.-S. (2015) Physical, Antioxidant and Structural Characterization of Blend Films Based on Hsian-Tsao Gum (HG) and Casein (CAS). Carbohydrate Polymers, 134, 222-229. https://doi.org/10.1016/j.carbpol.2015.07.021

[33] Beigomi, M., Mohsenzadeh, M., \& Salari, A. (2018). Characterization of a novel biodegradable edible film obtained from Dracocephalum moldavica seed mucilage. International Journal of Biological Macromolecules, 108, 874-883. https://doi.org/10.1016/j.ijbiomac.2017.10.184

[34] Khazaei, N., Esmaiili, M., Djomeh, Z.E., Ghasemlou, M. and Jouki, M. (2014) Characterization of New Biodegradable Edible Film Made from Basil Seed (Ocimum basilicum L.) Gum. Carbohydrate Polymers, 102, 199-206.

https://doi.org/10.1016/j.carbpol.2013.10.062

[35] Salarbashi, D., Mortazavi, S.A., Noghabi, M.S., Bazzaz, B.S.F., Sedaghat, N., Ramezani, M. and Shahabi-Ghahfarrokhi, I. (2016) Development of New Active Packaging Film Made from a Soluble Soybean Polysaccharide Incorporating ZnO Nanoparticles. Carbohydrate Polymers, 140, 220-227.

https://doi.org/10.1016/j.carbpol.2015.12.043

[36] Gheribi, R., Puchot, L., Verge, P., Jaoued-Grayaa, N., Mezni, M., Habibi, Y. and Khwaldia, K. (2018) Development of Plasticized Edible Films from Opuntia ficus-indica Mucilage: A Comparative Study of Various Polyol Plasticizers. Carbohydrate Polymers, 190, 204-211. https://doi.org/10.1016/j.carbpol.2018.02.085

[37] Faucard, P., Grimaud, F., Lourdin, D., Maigret, J.E., Moulis, C., Remaud-Siméon, M., Rolland-Sabaté, A., et al. (2018) Macromolecular Structure and Film Properties of Enzymatically-Engineered High Molar Mass Dextrans. Carbohydrate Polymers, 181, 337-344. https://doi.org/10.1016/j.carbpol.2017.10.065

[38] Sadeghi-Varkani, A., Emam-Djomeh, Z. and Askari, G. (2018) Physicochemical and Microstructural Properties of a Novel Edible Film Synthesized from Balangu Seed Mucilage. International Journal of Biological Macromolecules, 108, 1110-1119. https://doi.org/10.1016/j.ijbiomac.2017.11.029

[39] Memiş, S., Tornuk, F., Bozkurt, F. and Durak, M.Z. (2017) Production and Characterization of a New Biodegradable Fenugreek Seed Gum Based Active Nanocomposite Film Reinforced with Nanoclays. International Journal of Biological Macromolecules, 103, 669-675. https://doi.org/10.1016/j.ijbiomac.2017.05.090

[40] Zhang, X., Liu, C., Zhang, A. and Sun, R. (2018) Synergistic Effects of Graft Poly- 
merization and Polymer Blending on the Flexibility of Xylan-Based Films. Carbohydrate Polymers, 181, 1128-1135. https://doi.org/10.1016/j.carbpol.2017.11.025

[41] Mali, K.K., Dhawale, S.C. and Dias, R.J. (2017) Synthesis and Characterization of Hydrogel Films of Carboxymethyl Tamarind Gum Using Citric Acid. International Journal of Biological Macromolecules, 105, 463-470. https://doi.org/10.1016/j.ijbiomac.2017.07.058

[42] Leite, Á.J., Costa, R.R., Costa, A.M., Maciel, J.S., Costa, J.F., de Paula, R.C. and Mano, J.F. (2017) The Potential of Cashew Gum Functionalization as Building Blocks for Layer-by-Layer Films. Carbohydrate Polymers, 174, 849-857. https://doi.org/10.1016/j.carbpol.2017.06.055

[43] Zhang, Y., Pitkänen, L., Douglade, J., Tenkanen, M., Remond, C. and Joly, C. (2011) Wheat Bran Arabinoxylans: Chemical Structure and Film Properties of Three Isolated Fractions. Carbohydrate Polymers, 86, 852-859. https://doi.org/10.1016/j.carbpol.2011.05.036

[44] Sousa, S., Ramos, A., Evtuguin, D.V. and Gamelas, J.A. (2016) Xylan and Xylan Derivatives-Their Performance in Bio-Based Films and Effect of Glycerol Addition. Industrial Crops and Products, 94, 682-689. https://doi.org/10.1016/j.indcrop.2016.09.031

[45] Meireles, I.T., Huertas, R.M., Torres, Cristiana, A.V., Coelhoso, I.M. and Crespo, J.G. (2018) Development and Characterisation of Hybrid Polysaccharide Membranes for Dehydration Processes. Carbohydrate Polymers, 191, 216-224. https://doi.org/10.1016/j.carbpol.2018.03.010

[46] Raji, Z., Khodaiyan, F., Rezaei, K., Kiani, H. and Hosseini, S.S. (2017) Extraction Optimization and Physicochemical Properties of Pectin from Melon Peel. International Journal of Biological Macromolecules, 98, 709-716. https://doi.org/10.1016/j.ijbiomac.2017.01.146

[47] Petkowicz, C.L.O., Vriesmann, L.C. and Williams, P.A. (2017) Pectins from Food Waste: Extraction, Characterization and Properties of Watermelon Rind Pectin. Food Hydrocolloids, 65, 57-67. https://doi.org/10.1016/j.foodhyd.2016.10.040

[48] Jiang, L.N., et al. (2012) Comparisons of Microwave-Assisted and Conventional Heating Extraction of Pectin from Seed Watermelon Peel. Advanced Materials Research, 550-553, 1801-1806. https://doi.org/10.4028/www.scientific.net/AMR.550-553.1801

[49] Romdhane, M.B., Haddar, A., Ghazala, I., Jeddou, K.B., Helbert, C.B. and Ellouz-Chaabouni, S. (2017) Optimization of Polysaccharides Extraction from Watermelon Rinds: Structure, Functional and Biological Activities. Food Chemistry, 216, 355-364. https://doi.org/10.1016/j.foodchem.2016.08.056

[50] Ptitchkina, N.M., Danilova, I.A., Doxastakis, G., Kasapis, S. and Morris, E.R. (1994) Pumpkin Pectin: Gel Formation at Unusually Low Concentration. Carbohydrate Polymers, 23, 265-273. https://doi.org/10.1016/0144-8617(94)90189-9

[51] Kurz, C., Carle, R. and Schieber, A. (2008) Characterisation of Cell Wall Polysaccharide Profiles of Apricots (Prunus armeniaca L.), Peaches (Prunus persica L.), and Pumpkins (Cucurbita sp.) for the Evaluation of Fruit Product Authenticity. Food Chemistry, 106, 421-430. https://doi.org/10.1016/j.foodchem.2007.05.078

[52] Shkodina, O.G., Zeltser, O.A., Selivanov, N.Y. and Ignatov, V.V. (1998) Enzymic Extraction of Pectin Preparations from Pumpkin. Food Hydrocolloids, 12, 313-316. https://doi.org/10.1016/S0268-005X(98)00020-4

[53] Yang, X., Zhao, Y. and Lv, Y. (2007) Chemical Composition and Antioxidant Activity of an Acidic Polysaccharide Extracted from Cucurbita moschata Duchesne ex 
Poiret. Journal of Agricultural and Food Chemistry, 55, 4684-4690. https://doi.org/10.1021/jf070241r

[54] Huang, G., Chen, Y. and Wang, X. (2011) Extraction and Deproteinization of Pumpkin Polysaccharide. International Journal of Food Sciences and Nutrition, 62, 568-571. https://doi.org/10.3109/09637486.2011.560566

[55] Wu, L. and Jun-Mao, T. (2014) Extraction Technology of Polysaccharide from Seed Pumpkin. Academic Periodical of Farm. Products Processing, 2014-20.

[56] Wang, S., Lu, A., Zhang, L., Shen, M., Xu, T., Zhan, W., Wang, W., et al. (2017) Extraction and Purification of Pumpkin Polysaccharides and Their Hypoglycemic Effect. International Journal of Biological Macromolecules, 98, 182-187. https://doi.org/10.1016/j.ijbiomac.2017.01.114

[57] Yadav, M., Jain, S., Tomar, R., Prasad, G.B.K.S. and Yadav, H. (2010) Medicinal and Biological Potential of Pumpkin: An Updated Review. Nutrition Research Reviews, 23, 184-190. https://doi.org/10.1017/S0954422410000107

[58] Li, H., Ding, F., Xiao, L., Shi, R., Wang, H., Han, W. and Huang, Z. (2017) Food-Derived Antioxidant Polysaccharides and Their Pharmacological Potential in Neurodegenerative Diseases. Nutrients, 9, 778. https://doi.org/10.3390/nu9070778

[59] Jie, S., Guo-You, Y., Hua, Z., Lan-Ying, C., Yanqing, Z., Wen-Jan, L. and Xiao-Na, J. (2010) Extraction and Purification of Polysaccharide from Pumpkin and Their Antioxidant Activities in Progress. Journal of Henan University of Urban Construction, 2010-05.

[60] Hai-Jun, C. and Xiao-Yan, W. (2016) Extraction and Antioxidant Activity on Pumpkin Polysaccharide. Journal of Gansu Agricultural University, 2016-03.

[61] Jun, H.-I., Lee, C.-H., Song, G.-S. and Kim, Y.-S. (2006) Characterization of the Pectic Polysaccharides from Pumpkin Peel. LWT, 39, 554-561.

https://doi.org/10.1016/j.lwt.2005.03.004

[62] Wang, L., Liu, F., Wang, A., Yu, Z., Xu, Y. and Yang, Y. (2017) Purification, Characterization and Bioactivity Determination of a Novel Polysaccharide from Pumpkin (Cucurbita moschata) Seeds. Food Hydrocolloids, 66, 357-364. https://doi.org/10.1016/j.foodhyd.2016.12.003

[63] Sakurai, N., Tanaka, S. and Kuraishi, S. (1987) Changes in Wall Polysaccharides of Squash (Cucurbita maxima Duch.) Hypocotyls under Water Stress Condition I. Wall Sugar Composition and Growth as Affected by Water Stress. Plant Cell Physiology, 28, 1051-1058.

[64] Wakabayashi, K., Sakurai, N. and Kuraishi, S. (1991) Differential Effect of Auxin on Molecular Weight Distributions of Xyloglucans in Cell Walls of Outer and Inner Tissues from Segments of Dark Grown Squash (Cucurbita maxima Duch.) Hypocotyls. Plant Physiology, 95, 1070-1076. https://doi.org/10.1104/pp.95.4.1070

[65] Wakabayashi, K., Yamaura, K., Sakurai, N. and Kuraishi, S. (1993) Unchanged Molecular-Weight Distribution of Xyloglucans in Outer Tissue Cell Walls along Intact Growing Hypocotyls of Squash (Cucurbita maxima Duch.) Seedlings. Plant Cell Physiology, 34, 143-149.

[66] Koštálová, Z., Hromádková, Z. and Ebringerová, A. (2009) Chemical Evaluation of Seeded Fruit Biomass of Oil Pumpkin (Cucurbita pepo L. var. Styriaka). Chemical Papers, 63, 406-413. https://doi.org/10.2478/s11696-009-0035-5

[67] Kostálová, Z., Hromádková, Z. and Ebringerová, A. (2010) Isolation and Characterization of Pectic Polysaccharides from the Seeded Fruit of Oil Pumpkin (Cucurbita pepo L. var. Styriaca). Industrial Crops and Products, 31, 370-377. https://doi.org/10.1016/j.indcrop.2009.12.007 
[68] Kostálová, Z., Hromádková, Z., Ebringerová, A., Polovka, M., Michaelsen, T.E. and Paulsen, B.S. (2013) Polysaccharides from the Styrian Oil-Pumpkin with Antioxidant and Complement-Fixing Activity. Industrial Crops and Products, 41, 127-133. https://doi.org/10.1016/j.indcrop.2012.04.029

[69] Kostálová, Z., Hromádková, Z. and Ebringerová, A. (2013) Structural Diversity of pectins Isolated from the Styrian Oil-Pumpkin (Cucurbita pepo var. styriaca) Fruit. Carbohydrate Polymers, 93, 163-171. https://doi.org/10.1016/j.carbpol.2012.05.017

[70] Kostálová, Z., Aguedo, M. and Hromádková, Z. (2016) Microwave-Assisted Extraction of Pectin from Unutilized Pumpkin Biomass. Chemical Engineering and Processing, 102, 9-15. https://doi.org/10.1016/j.cep.2015.12.009

[71] Nosálová, G., Prisenžňáková, L. Koštálová, Z., Ebringerová, A. and Hromádková, Z. (2011) Suppressive Effect of Pectic Polysaccharides from Cucurbita pepo L. var. Styriaca on Citric Acid-Induced Cough Reflex in Guinea Pigs. Fitoterapia, 82, 357-364. https://doi.org/10.1016/j.fitote.2010.11.006

[72] Thomas, B. and Webb, J. (1977) Multiple Forms of $\alpha$-Galactosidase in Mature Leaves of Cucurbita pepo. Phytochemistry, 16, 203-206.

https://doi.org/10.1016/S0031-9422(00)86786-2

[73] Sedigheh, A., Jamal, M.S., Mahbubeh, S., Somayeh, K., Mahmoud, R.-K., Azadeh, A. and Fatemeh, S. (2011) Hypoglycaemic and Hypolipidemic Effects of Pumpkin (Cucurbita pepo L.) on Alloxan-Induced Diabetic Rats. African Journal of Pharmacy and Pharmacology, 5, 2620-2626.

[74] Song, Y., Li, J., Hu, X., Ni, Y. and Li, Q. (2011) Structural Characterization of a Polysaccharide Isolated from Lady Godiva Pumpkins (Cucurbita pepo lady godiva). Macromolecular Research, 19, 1172-1178. https://doi.org/10.1007/s13233-011-1102-7

[75] Song, Y., Yang, Y., Zhang, Y., Duan, L., Zhou, C., Ni, Y., Liao, X., Li, Q. and Hu, X. (2013) Effect of Acetylation on Antioxidant and Cytoprotective Activity of Polysaccharides Isolated from Pumpkin (Cucurbita pepo, lady godiva). Carbohydrate Polymers, 98, 686-691. https://doi.org/10.1016/j.carbpol.2013.06.049

[76] Song, Y., Ni, Y., Hu, X. and Li, Q. (2015) Effect of Phosphorylation on Antioxidant Activities of Pumpkin (Cucurbita pepo, Lady godiva) Polysaccharide. International Journal of Biological Macromolecules, 81, 41-48. https://doi.org/10.1016/j.ijbiomac.2015.07.055

[77] Alarcon-Aguilar, F.J., Hernandez-Galicia, E., Campos-Sepulveda, A.E., Xolalpa-Molina, S., Rivas-Vilchis, J.F., Vazquez-Carrillo, L.I. and Roman-Ramos, R. (2002) Evaluation of the Hypoglycemic Effect of Cucurbita ficifolia Bouché (Cucurbitaceae) in Different Experimental Models. Journal of Ethnopharmacology, 82, 185-189. https://doi.org/10.1016/S0378-8741(02)00176-9

[78] Xia, T. and Wang, Q. (2006) Antihyperglycemic Effect of Cucurbita ficifolia Fruit Extract in Streptozotocin-Induced Diabetic Rats. Fitoterapia, 77, 530-533. https://doi.org/10.1016/j.fitote.2006.06.008

[79] Simpson, R. and Morris, G.A. (2014) The Anti-Diabetic Potential of Polysaccharides Extracted from Members of the Cucurbit Family: A Review. Bioactive Carbohydrates and Dietary Fibre, 3, 106-114. https://doi.org/10.1016/j.bcdf.2014.03.003

[80] Garcia Gonzalez, J., Garcia Lorenzana, M., Zamilpa, A., Almanza Perez, J.C., Jasso Villagomez, E.I., Roman Ramos, R. and Alarcon-Aguilar, F.J. (2017) Chemical Characterization of a Hypoglycemic Extract from Cucurbita Ficifolia Bouche that Induces Liver Glycogen Accumulation in Diabetic Mice. African Journal of Traditional, Complementary and Alternative Medicine, 14, 218-230. 
https://doi.org/10.21010/ajtcam.v14i3.24

[81] Popović, S., Lazić, V., Popović, L., Vaštag, Ž. and Peričin, D. (2010) Effect of the Addition of Pumpkin Oil Cake to Gelatin to Produce Biodegradable Composite Films. International Journal of Food Science \& Technology, 45, 1184-1190. https://doi.org/10.1111/j.1365-2621.2010.02253.x

[82] Popović, S., Peričin, D., Vaštag, Ž., Popović, L. and Lazić, V. (2011) Evaluation of Edible Film-Forming Ability of Pumpkin oil Cake; Effect of $\mathrm{pH}$ and Temperature. Food Hydrocolloids, 25, 470-476. https://doi.org/10.1016/j.foodhyd.2010.07.022

[83] Popović, S., Peričin, D., Vaštag, Ž., Lazić, V. and Popović, L. (2012) Pumpkin Oil Cake Protein Isolate Films as Potential Gas Barrier Coating. Journal of Food Engineering, 110, 374-379. https://doi.org/10.1016/j.jfoodeng.2011.12.035

[84] Popović, S., Lazić, V., Hromiš, N., Šuput, D., Bulut, S., Popović, L. and Vaštag, Ž. (2015) Influence of Guar-Xanthan Addition on Mechanical Properties of Pumpkin oil Cake Biopolymer Films. Journal on Processing and Energy in Agriculture, 19, 179-182.

[85] Bulut, S., Lazić, V., Popović, S., Hromiš, N. and Šuput, D. (2017) Influence of Different Concentrations of Glycerol and Guar Xanthan on Properties of Pumpkin Oil Cake-Zein Bi-Layer Film. Ratarstvo i Povrtarstvo, 54, 19-24. https://doi.org/10.5937/ratpov54-11947

[86] Gomez-Diaz, D. and Navaza, J.M. (2003) Rheology of Aqueous Solutions of Food Additives Effect of Concentration, Temperature and Blending. Journal of Food Engineering, 56, 387-392. https://doi.org/10.1016/S0260-8774(02)00211-X

[87] Marchese, J. (1995) Procesos con Membranas. Editorial Universitaria, Universidad Nacional de San Luis, San Luis, Argentina.

[88] Zanon, M. and Masuelli, M. (2018) Purification and Characterization of Alcayota Gum. Experimental Reviews. In Press.

[89] Cerqueira, M., Pinheiro, A., Souza, B., Lima, A., Ribeiro, C., Miranda, C., Teixeira, J., Moreira, R., Coimbra, M., Goncalves, M. and Vicente, A. (2009) Extraction, Purification and Characterization of Galactomannans from Non-Traditional Sources. Carbohydrate Polymers, 75, 408-414. https://doi.org/10.1016/j.carbpol.2008.07.036

[90] Whistler, R. and Bemiller, J. (1958) Alkaline Degradation of Polysaccharides. Advances in Carbohydrate Chemistry, 13, 289-329. https://doi.org/10.1016/S0096-5332(08)60359-8

[91] Uçar, G. and Balaban, M. (2003) Hydrolysis of Polysaccharides with 77\% Sulfuric Acid for Quantitative Saccharification. Turkish Journal of Agriculture and Forestry, 27, 361-365.

[92] Glass, J.E. (1989) Polymers in Aqueous Media. American Chemical Society, USA. https://doi.org/10.1021/ba-1989-0223

[93] Cerqueira, M., Souza, B., Teixeira, J. And Vicente, A. (2012) Effect of Glycerol and Corn Oil on Physicochemical Properties of Polysaccharide Films: A Comparative Study. Food Hydrocolloids, 27, 175-184. https://doi.org/10.1016/j.foodhyd.2011.07.007

[94] Kuwajima, M. (2011) Cross-Linking Fixatives: What They Are, What They Do, and Why We Use Them. Kristen Harris Lab, USA.

[95] Crini, G. (2005) Recent Developments in Polysaccharide-Based Materials Used as Adsorbents in Wastewater Treatment. Progress in Polymer Science, 30, 38-70. https://doi.org/10.1016/j.progpolymsci.2004.11.002

[96] Masuelli, M., García, G., Marchese, J. and Ochoa, N. (2015) Development of Dense 
Films from Melia Azedarach Polysaccharides. Journal of Applied Polymer Science, 132, 41624. https://doi.org/10.1002/app.41624

[97] Da Silva, M. (2009) Alginate and Pectin Composite Crosslinked with $\mathrm{Ca}^{2+}$ Ions: Effect of the Plasticizer Concentration. Carbohydrate Polymers, 77, 738-739. https://doi.org/10.1016/j.carbpol.2009.02.014

[98] Meneses, J. (2007) Síntesis y caracterización de un polímero biodegradable a partir del almidón de yuca. Revista EIA, 8, 65-66.

[99] ASTM E95-96. Standard Test Methods for Water Vapor Transmission of Materials.

[100] ASTM D 6002-96-R02, 2005.

[101] Site visited in September, 2014. http://www.interempresas.net/Alimentaria/Articulos/27371-Area-tematica-Envases -para-el-sector-de-la-alimentacion.html

[102] Shastri, R. (2013) Handbook of Plastics Technologies. The Dow Chemical Company, USA.

[103] Siracusa, V. (2012) Food Packaging Permeability Behaviour: A Report. International Journal of Polymeric Science, 2012, Article ID: 302029. https://doi.org/10.1155/2012/302029

[104] Kauráková, M., Capek, P., Sasinková, V., Wellner, N. and Ebringerová, A. (2000) FT-IR Study of Plant Cell Wall Model Compounds: Pectic Polysaccharides and Hemicelluloses. Carbohydrate Polymers, 43, 195. https://doi.org/10.1016/S0144-8617(00)00151-X

[105] Capek, P., Bilisics, L., Kubackova, M., Alfoldi, J., VojtasïsÏak, J., Magdolen, P., LisÏkova, D., Kakoniova, D. and Sadlonova, K. (1998) Isolation and Structural Characterization of the Mannose-Rich Polysaccharide from the Wood of Picea abies L. Karst. In: Kurjatko, S. and Kudela, J., Eds., Wood Structure and Properties, Arbora, Zvolen, Slovakia, 19-21.

[106] Szymanska-Chargot, M., Chylinska, M., Kruk, B. and Zdunek, A. (2015) Combining FT-IR Spectroscopy and Multivariate Analysis for Qualitative and Quantitative Analysis of the Cell Wall Composition Changes during Apples Development. Carbohydrate Polymers, 115, 93-103. https://doi.org/10.1016/j.carbpol.2014.08.039

[107] Romdhane, M.B., Haddar, A., Ghazala, I., Jeddou, K.B., Helbert, C.B. and Ellouz-Chaabouni, S. (2017) Optimization of Polysaccharides Extraction from Watermelon Rinds: Structure, Functional and Biological Activities. Food Chemistry, 216, 355-364. https://doi.org/10.1016/j.foodchem.2016.08.056

[108] Park, F.S. (1971) Application of Infrared Spectroscopy in Biochemistry, Biology and Medicine. Plenum Press, New York, 100-140. https://doi.org/10.1007/978-1-4684-1872-9_6

[109] Cao, W., Li, X. Q., Liu, L., Wang, M., Fan, H. T., Li, C., Mei, Q., et al. (2006) Structural Analysis of Water-Soluble Glucans from the Root of Angelica sinensis (Oliv.) Diels. Carbohydrate Research, 341, 1870-1877. https://doi.org/10.1016/j.carres.2006.04.017

[110] Barker, S.A., Bourne, E.J., Stacey, M. and Whiffen, D.H. (1954) Infra-Red Spectra of Carbohydrates. Part I. Some Derivatives of D-Glucopyranose. Journal of the Chemical Society (Resumed), 1954, 171-176. https://doi.org/10.1039/jr9540000171

[111] Barker, S.A., Bourne, E.J., Stephens, R. and Whiffen, D.H. (1954) Infra-Red Spectra of Carbohydrates. Part II. Anomeric Configuration of Some Hexo- and Pento-Pyranoses. Journal of the Chemical Society (Resumed), 1954, 3468-3473.

[112] Song, Y., Li, J., Hu, X., Ni, Y. and Li, Q. (2011) Structural Characterization of a Po- 
lysaccharide Isolated from Lady Godiva Pumpkins (Cucurbita pepo lady godiva). Macromolecular Research, 19, 1172.

[113] Qu, Y., Li, C., Zhang, C., Zeng, R. and Fu, C. (2016) Optimization of Infrared-Assisted Extraction of Bletilla striata Polysaccharides Based on Response Surface Methodology and Their Antioxidant Activities. Carbohydrate Polymers, 148, 345-353. https://doi.org/10.1016/j.carbpol.2016.04.081

[114] Kapoor, V.P., Taravel, F.R., Joseleau, J.P., Milas, M., Chanzy, H. and Rinaudo, M. (1998) Cassia Spectabilis DC Seed Galactomannan: Structural, Crystallographical and Rheological Studies. Carbohydrate Research, 306, 231-241. https://doi.org/10.1016/S0008-6215(97)00241-3

[115] Kapoor, V.P., Chanzy, H. and Taravel, F.R. (1995) X-Ray Diffraction Studies on Some Seed Galactomannans from India. Carbohydrate Polymers, 27, 229-233. https://doi.org/10.1016/0144-8617(95)00045-9

[116] Masuelli, M.A. and García, M.G. (2017) Biopackaging: Tara Gum Films. In: Masuelli, M. and Renard, D. Eds., Advances in Physicochemical Properties of Biopolymers, Part 2, Editorial Bentham Publishing, 876-898.

[117] Vendruscolo, C.W., Ferrero, C., Pineda, E.A., Silveira, J.L., Freitas, R.A., Jiménez-Castellanos, M.R. and Bresolin, T.M. (2009). Physicochemical and Mechanical Characterization of Galactomannan from Mimosa scabrella: Effect of Drying Method. Carbohydrate Polymers, 76, 86-93. https://doi.org/10.1016/j.carbpol.2008.09.028

[118] Das, D., Ara, T., Dutta, S. and Mukherjee, A. (2011) New Water Resistant Biomaterial Biocide Film Based on Guar Gum. Bioresource Technology, 102, 5878-5883. https://doi.org/10.1016/j.biortech.2011.02.034

[119] Cerqueira, M.A., Souza, B.W., Simões, J., Teixeira, J.A., Domingues, M.R.M., Coimbra, M.A. and Vicente, A.A. (2011) Structural and Thermal Characterization of Galactomannans from Non-Conventional Sources. Carbohydrate Polymers, 83, 179-185. https://doi.org/10.1016/j.carbpol.2010.07.036

[120] Antoniou, J., Liu, F., Majeed, H. and Zhong, F. (2015) Characterization of Tara Gum Edible Films Incorporated with Bulk Chitosan and Chitosan Nanoparticles: A Comparative Study. Food Hydrocolloids, 44, 309-319. https://doi.org/10.1016/j.foodhyd.2014.09.023

[121] Naoi, S., Hatakeyama, T. and Hatakeyama, H. (2002) Phase Transition of Locust Bean Gum-, Tara Gum- and Guar Gum-Water Systems. Journal of Thermal Analysis and Calorimetry, 70, 841-852. https://doi.org/10.1023/A:1022260304686

[122] Antoniou, J., Liu, F., Majeed, H., Qazi, H.J. and Zhong, F. (2014) Physicochemical and Thermomechanical Characterization of Tara Gum Edible films: Effect of Polyols as Plasticizers. Carbohydrate Polymers, 111, 359-365. https://doi.org/10.1016/j.carbpol.2014.04.005

[123] Cristiano, C.M., Fayad, S.J., Porto, L.C. and Soldi, V. (2010) Protein-Based Films Cross-Linked with 1-Ethyl-3-(3-dimethylamino-propyl) Carbodiimide Hydrochloride (EDC): Effects of the Cross-Linker and Film Composition on the Permeation Rate of p-Hydroxyacetanilide as a Model Drug. Journal of the Brazilian Chemical Society, 21, 340-348. https://doi.org/10.1590/S0103-50532010000200021

[124] Yuan, C., Chen, M., Luo, J., Li, X., Gao, Q. and Li, J. (2017) A Novel Water-Based Process Produces Eco-Friendly Bio-Adhesive Made from Green Cross-Linked Soybean Soluble Polysaccharide and Soy Protein. Carbohydrate Polymers, 169, 417-425. https://doi.org/10.1016/j.carbpol.2017.04.058

[125] Thijs, H.M., Becer, C.R., Guerrero-Sanchez, C., Fournier, D., Hoogenboom, R. and Schubert, U.S. (2007) Water Uptake of Hydrophilic Polymers Determined by a 
Thermal Gravimetric Analyzer with a Controlled Humidity Chamber. Journal of Materials Chemistry, 17, 4864-4871. https://doi.org/10.1039/b711990a

[126] Zhang, Y. (2011) Wheat Bran Arabinoxylans: Chemical Structure and Film Properties of Three Isolated Fractions. Carbohydrate Polymers, 86, 857-858.

https://doi.org/10.1016/j.carbpol.2011.05.036

[127] Andreuccetti, C., Carvalho, R. and Grosso, C. (2009) Effect of Hydrophobic Plasticizers on Functional Properties of Gelatin-Based Films. Food Research International, 42, 1113-1121. https://doi.org/10.1016/j.foodres.2009.05.010

[128] Bertuzzi, M., Armada, M., Gottifredi, J., Aparicio, A. and Jiménez, P. (2002) Estudio de la permeabilidad al vapor de agua de films comestibles para recubrir alimentos. Congreso Regional de Ciencia y Tecnología NOA 2002. Universidad Nacional de Catamarca.

[129] Bertuzzi, M.A., Vidaurre, E.C., Armada, M. and Gottifredi, J.C. (2007) Water Vapor Permeability of Edible Starch Based Films. Journal of Food Engineering, 80, 972-978. https://doi.org/10.1016/j.jfoodeng.2006.07.016

[130] Anilkumar, S. (2003) Permeation of Oxygen and Nitrogen Gases through Crosslinked EVA Membranes. India.

[131] Bertuzzi, M.A., Armada, M. and Gottifredi, J.C. (2007) Physicochemical Characterization of Starch Based Films. Journal of Food Engineering, 82, 17-25. https://doi.org/10.1016/j.jfoodeng.2006.12.016

[132] Yang, L. and Paulson, A.T. (2000) Mechanical and Water Vapour Barrier Properties of Edible Gellan Films. Food Research International, 33, 563-570. https://doi.org/10.1016/S0963-9969(00)00092-2

[133] Masuelli, M., García, G., Ochoa, A. and Marchese, J. (2012) Preparación de Films de Pectina para el Envasado de Alimentos. Congreso Iberoamericano de Ciencia y Tecnología en Membranas, Salta, Argentina.

[134] Pavlath, A., Voisin, A. and Robertson, G. (1999) Pectin-Based Biodegradable Water Insoluble Films. Macromolecular Symposia, 140, 107-113. https://doi.org/10.1002/masy.19991400112

[135] Jiménez, A., Fabra, M.J., Talens, P. and Chiralt, A. (2012) Edible and Biodegradable Starch Films: A Review. Food and Bioprocess Technology, 5, 2058-2076. https://doi.org/10.1007/s11947-012-0835-4

[136] Denavi, G.A., Pérez-Mateos, M., Añón, M.C., Montero, P., Mauri, A.N. and Gomez-Guillen, M.C. (2009) Structural and Functional Properties of Soy Protein Isolate and Cod Gelatin Blend Films. Food Hydrocolloids, 23, 2094-2101. https://doi.org/10.1016/j.foodhyd.2009.03.007

[137] Gómez Estaca, J., Gómez Guillén, M. and Fernandez, M. (2011) Effects of Gelatin Origin, Bovine-Hide and Tuna-Skin, on the Properties of Compound Gelatin-Chitosan Films. Food Hydrocolloids, 25, 1461-1469. https://doi.org/10.1016/j.foodhyd.2011.01.007

[138] Kurt, A. and Kahyaoglu, T. (2014) Characterization of a New Biodegradable Edible Film Made from Salep Glucomannan. Carbohydrate Polymers, 104, 50-58. https://doi.org/10.1016/j.carbpol.2014.01.003

[139] Masuelli, Martin A. and Zanon, M. (2017) Rheology of Alcayota Gum. Journal of Chemical Engineering and Process Technology, 8, No. 4 (Suppl), as only abstract. https://doi.org/10.4172/2157-7048-C1-005

[140] Masuelli, M.A. (2016) Alcayota Films: Effect of Crosslinking. Journal of Advanced Chemical Engineering, 6, No. 3 (Suppl), as only abstract. https://doi.org/10.4172/2090-4568.C1.002 